\title{
Optimal assessment and management of chronic obstructive pulmonary disease (COPD)
}

\author{
N.M. Siafakas, P. Vermeire, N.B. Pride, P. Paoletti, J. Gibson, P. Howard, \\ J.C. Yernault, M. Decramer, T. Higenbottam, D.S. Postma, J. Rees, \\ on behalf of the Task Force
}

A consensus statement of the European Respiratory Society (ERS)

\author{
Contents \\ Foreword \\ Introduction \\ Assessment \\ Treatment \\ Management \\ Special Considerations \\ Appendix A: Pathology \\ Appendix B: Pathophysiology \\ Appendix C: Epidemiology
}

\section{Foreword}

Chronic obstructive pulmonary disease (COPD) is a major cause of morbidity and mortality. In the European Union, COPD and asthma, together with pneumonia, are the third most common cause of death. In North America, COPD is the fourth leading cause of death, and mortality rates and prevalence are increasing.

The major characteristic of COPD is the presence of chronic airflow limitation that progresses slowly over a period of years and is, by definition, largely irreversible. Most patients with COPD are, or were, cigarette smokers. Prevention by reducing the prevalence of smoking remains a priority. Although much of the damage is irreversible at the time of clinical presentation, treatments are available to improve the quality of life, the life expectancy, and perhaps the functional ability of patients with COPD.

Several national and international consensus statements on optimal assessment and management of asthma have been published in recent years. These consensus statements have led to international standardization of diagnosis and management and to better care. They also form a basis for clinical audits and suggest areas of future research. However, there have been few attempts to develop consensus guidelines on management of COPD [1, 2].

The European Respiratory Society (ERS) has taken the initiative of producing a consensus statement on COPD. A Task Force of scientists and clinicians was invited to provide this European consensus. The guidelines are intended for use by physicians involved in the care of patients with COPD, and their main goals are to inform health professionals and to reverse a widespread nihilistic approach to the management of these patients. This Task Force firmly believes that treatment can significantly improve the quality and length of life of patients suffering from this chronic, progressive condition.

Subcommittees of the Task Force focused on the five main sections of this project: Pathology/Pathophysiology, Epidemiology, Assessment, Treatment, and Management. Experts produced papers within each section, and these papers were brought together by the subcommittee heads. At a plenary meeting held in Wiesbaden, Germany on November 11-13, 1993, all contributions were extensively discussed, and additional working group meetings were arranged. Flowcharts for management in common clinical situations were produced. However, at all stages, members of the Task Force found themselves confronted by unresolved questions and regional differences in management across Europe. A practical approach was adopted, combining established scientific evidence and a consensus view when current data were inadequate. This approach identified more clearly those areas where further research is needed.

Comments on drafts of the consensus statement were invited from participants of the original meeting, which included colleagues from North America. The edited document was sent to independent experts for external review. All members had an opportunity to comment on the document at the ERS meeting in Nice on October 2, 1994.

As chairmen of the Task Force, we hope that the final document will promote better management of COPD in Europe. We would like to thank all who contributed to it. On behalf of the ERS, we also gratefully acknowledge a generous educational grant from Boehringer Ingelheim and the organizational assistance provided by M.T. Lopez-Vidriero.

N.M. Siafakas, P. Vermeire 


\section{References}

1. American Thoracic Society. Standards for the diagnosis and care of patients with chronic obstructive pulmonary disease (COPD) and asthma. Am Rev Respir Dis 1987; 136: 225-244.

2. Chapman KR, Bowie DM, Goldstein RS, et al. Guidelines for the assessment and management of chronic obstructive pulmonary disease. Canadian Thoracic Society Workshop Group. Can Med Assoc J 1992; 147: 420-428.

\section{Introduction}

\section{Definitions}

Chronic obstructive pulmonary disease (COPD) is a disorder characterized by reduced maximum expiratory flow and slow forced emptying of the lungs; features which do not change markedly over several months [1]. Most of the airflow limitation is slowly progressive and irreversible. The airflow limitation is due to varying combinations of airway disease and emphysema; the relative contribution of the two processes is difficult to define in vivo. The airway component consists mainly of decreased luminal diameters due to various combinations of increased wall thickening, increased intraluminal mucus, and changes in the lining fluid of the small airways.

Emphysema is defined anatomically by permanent, destructive enlargement of airspaces distal to the terminal bronchioles without obvious fibrosis [2]. Loss of alveolar attachments to the airway perimeter contributes to airway stenosis. Pathological changes occurring in COPD are discussed more extensively in Appendix A.

Chronic bronchitis is defined by the presence of chronic or recurrent increases in bronchial secretions sufficient to cause expectoration. The secretions are present on most days for a minimum of 3 months a year, for at least two successive years, and cannot be attributed to other pulmonary or cardiac causes $[3,4]$. This hypersecretion can occur in the absence of airflow limitation.

Patients with COPD often exhibit minimal reversibility of airflow limitation with bronchodilators. Airway hyperresponsiveness to a variety of constrictor stimuli is common. These patients often have recurrent or persistent productive cough.

\section{Differential diagnosis}

The most difficult diagnostic problem is distinguishing COPD from the persistent airflow limitation of chronic asthma in older subjects. Although the distinction may sometimes be impossible, the presence or absence of some clinical features may help in distinguishing between the two conditions. A history of heavy smoking, evidence of emphysema on imaging, decreased diffusing capacity, and chronic hypoxaemia favour the diagnosis of COPD. In contrast, atopy and marked improvement on spirometry with administration of bronchodilators or glucocorticosteroids favour the diagnosis of asthma.
A number of specific causes of chronic airflow limitation have, by convention, been excluded from COPD. These include cystic fibrosis, bronchiectasis, and bronchiolitis obliterans (associated with transplantation, chemical inhalation, severe viral infection, and other causes).

\section{Pathophysiology}

Aspects of the pathophysiology of COPD are presented in Appendix B. Changes occurring during the evolution of the disease, in either the presence or absence of emphysema, acute exacerbations and respiratory failure are discussed.

\section{Epidemiology and natural history}

The incidence, morbidity, and mortality from COPD are rising, but they vary widely between countries. The main risk factors are cigarette smoking and occupational exposure. There are, however, large variations in individual susceptibility.

This disease is often diagnosed late in its course, because patients may lack symptoms, even at low forced expiratory volume in one second $(\mathrm{FEV} 1)$. Frequent routine spirometry allows earlier detection of COPD. The main factor associated with rapid longitudinal decline in FEV1 and poor prognosis is persistent smoking. Cessation of smoking reduces the rapid decline in FEV1. Therefore, active intervention to help patients stop smoking is the primary tool for adequate management of COPD.

A more extensive overview of the epidemiology and natural history of COPD is presented in Appendix C.

\section{References}

1. American Thoracic Society. Standards for the diagnosis and care of patients with chronic obstructive pulmonary disease (COPD) and asthma. Am Rev Respir Dis 1987; 136: 225-244.

2. Snider GL, Kleinerman J, Thurlbeck WM, Bengali ZH. The definition of emphysema: report of a National Heart and Blood Institute, Division of Lung Diseases, workshop. Am Rev Respir Dis 1985; 132: 182-185.

3. Medical Research Council. Definition and classification of chronic bronchitis, clinical and epidemiological purposes: a report to the Medical Research Council by their committee on the etiology of chronic bronchitis. Lancet 1965; i: 775-780.

4. Fletcher CM, Pride NB. Definitions of emphysema, chronic bronchitis, asthma, and airflow obstruction: 25 years on from the Ciba symposium. Thorax 1984; 39: $81-85$

\section{Assessment}

\section{Symptoms [1]}

The two main symptoms that cause patients with COPD to consult a physician are breathlessness and 
cough, sometimes accompanied by wheezing or sputum production. A history of repeated respiratory infections, especially during the winter, is common. Most patients are long-term cigarette smokers.

Breathlessness develops gradually over many years and eventually limits daily activities. By the time patients present with breathlessness, they are usually more than $40 \mathrm{yrs}$ of age and have functional evidence of moderate or severe airflow limitation. Breathlessness and exercise capacity should be assessed by questions related to everyday activities, such as those found in standard questionnaires [2, 3].

Chronic cough, which is often productive and worse in the morning, is present in most patients, dominating the clinical picture in some cases. However, it bears no relationship to the severity of the functional deficit. The amount and character of sputum can provide useful information, especially when there is an increase in volume or purulence, which may indicate an exacerbation. Persistent large volumes of sputum (e.g. $\left.30 \mathrm{~mL} \cdot 24 \mathrm{~h}^{-1}\right)$, especially if purulent, are suggestive of bronchiectasis. Haemoptysis is not uncommon during exacerbations, so that purulent sputum may be blood-streaked; however, the presence of blood should always alert the physician to the possibility of alternative diagnoses.

Obesity contributes to breathlessness in some individuals. In advanced COPD, however, anorexia and weight loss are common. Weight loss is associated with more severe impairment of lung function. Sleep-related symptoms, particularly daytime sleepiness and heavy snoring, should raise suspicion for coexisting obstructive sleep apnoea, which is particularly common in obese patients.

\section{Physical findings [1]}

The physical signs in patients with COPD depend on the degree of airflow limitation, the severity of pulmonary hyperinflation, and body build. The sensitivity of physical examination for detecting or excluding moderately severe COPD is poor, and reproducibility of physical signs is variable [4]. Among the classical physical signs, wheezing during tidal breathing and prolonged forced expiratory time $(>5 \mathrm{~s})$ are useful indicators of airflow limitation. These signs, however, are of no value as guides to severity, and their absence does not exclude COPD. Other signs, such as diminished breath sounds, reduced ribcage expansion and diaphragmatic excursion, and hyperresonance may be elicited; again, they are poor guides to the degree of airflow limitation. Visible activity of accessory muscles (e.g. the sternomastoid) or pursedlip breathing usually imply severe airflow obstruction. Central cyanosis is seen with significant hypoxaemia, but its sensitivity is low, and it is influenced by other factors (e.g. haemoglobin concentration).

Peripheral oedema, raised jugular venous pressure, hepatic enlargement, and signs of pulmonary hypertension are seen with the development of cor pulmonale. Oedema may, however, be due to other causes, such as altered renal function, which is common in patients with hypoxaemia and hypercapnia [5].
During exacerbations, the clinical findings depend on the degree of additional airflow limitation, the severity of the underlying COPD, and the presence of coexisting conditions. The severity of an exacerbation is assessed crudely by tachypnoea, tachycardia, use of accessory respiratory muscles, cyanosis, and evidence of respiratory muscle dysfunction or fatigue (e.g. uncoordinated ribcage motion or paradoxical movement of the abdominal wall during inspiration). The classic signs of hypercapnia are inconsistent and unreliable. The poor sensitivity of symptoms and signs emphasizes the need for objective measurements. If the severity of an exacerbation is in doubt, it should always be assessed in hospital (see section on "Management").

Historically, patients with COPD have been classified as "pink puffers" and "blue bloaters". Many patients fall into neither group. Contrary to earlier thinking, these descriptive terms are not clearly related to specific functional or pathological features, and their use is not encouraged.

\section{Investigations}

\section{Lung function tests}

Lung function tests are used in the diagnosis of COPD as well as in the assessment of its severity, progression and prognosis. The presence of airflow limitation is recognized by a reduction in the ratio of FEV1 to vital capacity (VC) or forced vital capacity (FVC). The FEV1/VC ratio is a relatively sensitive index of mild COPD. In moderate to severe disease, the severity of airflow limtation is best assessed by the FEV1 in relation to reference values [6].

A suggested, categorization of patients with COPD in terms of FEV1 is shown in table 1. Any such grading is inevitably arbitrary, however.

Most studies of lung function in COPD are based on FEV1, because it shows the least variability. Several other indices can be measured during forced expiration. An example is maximal mid-expiratory flow or maximal expiratory flow $\left(V^{\prime} \max \right)$ at a given lung volume (e.g. maximal expiratory flow at $\left.50 \% \mathrm{VC}\left(V^{\prime} \max 50\right)\right)$. Because of greater intrasubject and intersubject variability, resulting in a larger range of predicted values, such indices

Table 1. - Severity of COPD based on FEV 1

\begin{tabular}{lc}
\hline Severity & $\begin{array}{c}\text { FEV } 1^{*} \\
\% \text { pred }\end{array}$ \\
\hline Mild & $\geq 70$ \\
Moderate & $50-69$ \\
Severe & $<50$ \\
\hline
\end{tabular}

*: in the presence of obstruction assessed as $\mathrm{FEV}_{1} / \mathrm{VC}^{2}<88 \%$ predicted in men or $<89 \%$ predicted in women (i.e. $>1.64$ residual standard deviation below predicted value). COPD: chronic obstructive pulmonary disease; FEV1: forced expiratory volume in one second; VC: vital capacity; $\%$ pred: percentage of predicted value. 
do not provide information that is more useful in clinical practice than that provided by FEV1 and VC.

Peak expiratory flow (PEF) is more convenient for domiciliary monitoring of airway function. This measurement is sometimes used to assess response to treatment or to document diurnal variation. In advanced emphysema, however, the PEF should not be relied on, as it may be only moderately reduced, whilst the FEV1 is severely affected.

\section{Resistance measurements}

Airways resistance can be measured by whole-body plethysmography, and respiratory resistance can be assessed by the forced oscillation technique. These measurements provide information about the calibre of the uncompressed airway as resistance is measured during quiet breathing or panting. The forced oscillation technique is less dependent on the co-operation of the subject. In most situations, resistance measurements have no clinical advantage over measurement of FEV1.

\section{Response to bronchodilators, corticosteroids and broncho- constrictors}

Most individuals with COPD show an increase of FEV1 following inhalation of sympathomimetic or anticholinergic drugs. Different criteria of reversibility have been used [7]. Percentage increases from baseline are of limited value because of their dependence on the pretreatment level. Expression of reversibility as an absolute change or as a percentage of predicted value is more reproducible and independent of baseline FEV1. However, symptomatic improvement may occur without a significant increase in FEV1 [7, 8].

In stable COPD, an increase in FEV 1 following a therapeutic trial of corticosteroids for several days is often taken as an indication for regular use of these drugs, in either oral or inhaled form. An increase $\geq 10 \%$ of the predicted value has been used to define a positive steroid response [9].

Many patients show airway hyperresponsiveness to inhaled histamine or methacholine. The response is largely dependent on prechallenge airway function. Testing of bronchoconstrictor response is of doubtful clinical value in patients with established airflow limitation.

\section{Static lung volumes and distensibility}

Functional residual capacity (FRC), residual volume (RV), and the ratio of RV to total lung capacity (TLC) are characteristically increased in COPD. In particular, TLC is increased in those patients with severe emphysema. An increase in static pulmonary compliance, a decrease in lung recoil pressure at a given lung volume, and a change in the shape of the static pressure-volume curve of the lung (defined by the shape factor, $\kappa$ ) are characteristic of pulmonary emphysema. Such measurements are not widely applied in clinical assessment.

\section{Respiratory muscle function}

Maximum inspiratory and expiratory pressures $(P I, \max$ and $P$ E,max, respectively) are reduced in many patients with COPD. Whereas PI,max is impaired by hyperinflation due to shortening of the inspiratory muscles, $P$ E,max is less influenced by respiratory mechanics. Reduction in $P$ E,max can be attributed to muscle weakness, which is common in advanced COPD [10]. Measurement of maximum respiratory pressures is indicated if poor nutrition or steroid myopathy is suspected, or if dyspnoea or hypercapnia are out of proportion to the FEV1.

\section{Transfer factor}

A reduction in the single-breath carbon monoxide transfer factor $(T \mathrm{~L}, \mathrm{CO})$, is usually present in patients with symptomatic COPD. The transfer coefficient $(K \mathrm{CO})$ is the best functional indicator of the presence and severity of emphysema. Although nonspecific, the measurement is of clinical value in distinguishing patients with emphysema from those with asthma, in whom $\mathrm{KCO}$ is generally not reduced.

\section{Arterial blood gas tensions}

The relationship between FEV1 and arterial blood gas tensions is weak. However, measurement of blood gas tensions with the patient breathing room air is recommended in the assessment of patients with moderate or severe stable COPD. An alternative approach in patients with moderate COPD is to measure arterial oxygen saturation $\left(\mathrm{Sa}_{\mathrm{a}} \mathrm{O}_{2}\right)$ using an oximeter. If the value is $\leq 92 \%$, blood gas tensions should be measured.

Sequential measurements of blood gas tensions are necessary to follow the impairment of gas exchange, and are of paramount importance in the management of respiratory failure [11].

\section{Exercise testing}

Assessment of exercise performance is of particular value in patients whose breathlessness appears to be out of proportion to simple measurements, such as FEV1. Exercise testing also helps select and follow patients in a pulmonary rehabilitation programme. The use of simple walking tests (e.g. a 6 min walk) is sometimes advocated for assessing and evaluating the response to treatment, but the reproducibility of such tests is generally poor [12].

\section{Assessment of progression}

Serial measurements of FEV1 are used to monitor the progression of the disease. Longitudinal studies of the decline in FEV1 yield varying results; however, a decrease of $>50 \mathrm{~mL} \cdot \mathrm{yr}^{-1}$ suggests accelerated progression [13]. 
Because of the variability of the measurements, confident assessment of the rate of decline in an individual patient requires periodic measurements of FEV1 over at least 4 yrs [13].

\section{Pulmonary circulation}

Pulmonary hypertension is frequently present in advanced COPD, and its severity is related to the prognosis [14]. In recent years, noninvasive methods have been developed for assessing the presence and degree of pulmonary hypertension in patients with COPD. The best results have been obtained with Doppler echocardiography, but correlation with measured systolic pulmonary artery pressure is not sufficiently close for accurate estimation in an individual patient [15]. Right heart catheterization remains the only way to accurately measure pulmonary vascular pressures. However, because similar prognostic information can be obtained in COPD patients from simpler measurements, such as FEV1 and blood gases, routine catheterization is not recommended.

\section{Investigation during sleep}

Patients with COPD may have worsening hypoxaemia and hypercapnia during sleep, particularly during rapid eye movement (REM) sleep. The blood gas abnormalities during REM sleep are accompanied by a rise in pulmonary artery pressure. Although patients with nocturnal oxygen desaturation have significantly greater pulmonary artery pressure and pulmonary vascular resistance than those without nocturnal desaturation [16], the contribution of isolated nocturnal hypoxaemia to pulmonary hypertension is uncertain. In general, more severe nocturnal desaturation is associated with low daytime arterial oxygen pressure $\left(\mathrm{Pa}_{\mathrm{a}} \mathrm{O}_{2}\right)$, although the correlation is not very close. Other possible consequences of oxygen desaturation during sleep include cardiac arrhythmias and polycythaemia.

The need for nocturnal studies in routine assessment of patients with COPD is controversial. Detailed sleep studies (polysomnography) are indicated if coexisting obstructive sleep apnoea (the so-called overlap syndrome) is suspected. Measurement of nocturnal oxygenation may also be helpful in the presence of other unexplained features, such as cor pulmonale or polycythaemia despite relatively mild airway obstruction. Further research is needed on the prognostic value of sleep measurements for assessing nocturnal desaturation in individuals with moderately severe daytime hypoxaemia (arterial oxygen tension $\left(\mathrm{Pa}_{\mathrm{a}} \mathrm{O}_{2}\right) 7.3-8.7 \mathrm{kPa}(55-65$ $\mathrm{mmHg})$ ). With current criteria, such hypoxaemia is not generally regarded as an indication for long-term oxygen treatment.

\section{Radiology}

Plain chest radiography. Although a plain chest radiograph is not sensitive for the diagnosis of COPD, it is useful in the initial assessment. Depression and flattening of the diaphragm on the posteroanterior film and increase in the retrosternal airspace on the lateral chest radiograph are well-recognized signs of hyperinflation. Bullae and/or irregular radiolucency of the lung fields (absence of vasculature) may be obvious in severe cases of emphysema, but their recognition is subjective and dependent on the quality of the radiograph. The presence of such abnormalities is considered specific for emphysema in a patient with COPD [17]. However, the extent of emphysema diagnosed radiographically is poorly correlated with its severity at necropsy [18]. At presentation of patients with COPD, the plain chest radiograph can exclude other conditions, such as lung cancer. It may also suggest cor pulmonale and pulmonary hypertension; if the maximum diameter of the right descending pulmonary artery exceeds $16 \mathrm{~mm}$, then pulmonary hypertension is likely [19]. In acute exacerbations of COPD, a chest radiograph is important to confirm or exclude complicating pneumonia or pneumothorax.

Computed tomography $(C T)$. Computed tomography provides a means of measuring tissue density. Emphysema reduces lung density, and this can be visualized as low attenuation areas on the CT scan. The finding can be quantified by measuring the frequency distribution of density values from each picture element [20]. Recent evidence suggests that high-resolution CT scanning is sufficiently sensitive to diagnose emphysema in patients with normal chest radiographs and isolated low transfer factor [21]. It appears to be useful in identifying patterns of emphysema, such as centriacinar and panacinar emphysema [22]. The size and number of bullae can be quantified accurately by CT scanning. Knowledge of the extent of emphysema in the nonbullous lung may be useful in predicting the outcome of surgical treatment.

Despite these uses, CT scanning is not recommended for routine clinical assessment. Its role in patients with COPD is limited to evaluation of bullae and investigation of coexisting bronchiectasis.

\section{Quality of life}

Recently, questionnaires to assess quality of life have been introduced and evaluated in patients with COPD $[3,8,23]$. These tools are being used increasingly in studies of the effects of treatment, and may prove to be sensitive means of measuring the progression of the disease. However, none of the questionnaires is as yet generally accepted for use in everyday clinical practice.

\section{Summary of initial assessment and follow-up}

The investigations recommended for diagnosis and initial assessment of COPD are summarized in table 2. In follow-up assessment, spirometry is essential. If arterial blood gas tensions are abnormal at the initial assessment, they should be monitored. Otherwise, further investigations will usually depend on changes in spirometric volumes. 
Table 2. - Investigations for diagnosis and initial assessment

\begin{tabular}{ll}
\hline Indication & Test \\
\hline Routine & FEV1 \\
& VC or FVC \\
& Bronchodilator response \\
& Chest radiograph \\
& TL,CO/KCO \\
& Lung volumes \\
Specific indications & $\mathrm{S}_{2}$ and/or blood gases \\
Moderate or severe COPD & Electrocardiogram \\
& Haemoglobin \\
& Sputum culture and \\
sensitivity & $\alpha_{1}$-antitrypsin level \\
Persistent purulent sputum & CT scan \\
& Exercise test \\
Emphysema in younger & Maximum respiratory \\
patients & pressures \\
Assessment of bullae & Bronchoconstrictor response \\
Disproportionate breathlesssness & PEF monitoring \\
& Nocturnal sleep study \\
Suspected asthma & \\
Suspected obstructive sleep &
\end{tabular}

FVC: forced vital capacity; TL,CO: transfer factor of the lungs for carbon monoxide; KCO: carbon monoxide transfer coefficient; $\mathrm{Sa}, \mathrm{O}_{2}$ : arterial oxygen saturation; $\mathrm{CT}$ : computed tomography; PEF: peak expiratory flow.

\section{References}

1. Georgopoulos D, Anthonisen NR. Symptoms and signs of COPD. In: Cherniack N, ed. Chronic obstructive pulmonary disease. Saunders, N.Y. 1990; pp. 357-363.

2. Mahler DA, Wells CK. Evaluation of clinical methods for rating dyspnoea. Chest 1988; 93: 580-586.

3. Mahler DA, Faryniarz RN, Tomlinson D, et al. Impact of dyspnea and physiologic function on general health status in patients with chronic obstructive pulmonary disease. Chest 1992; 102: 395-401.

4. Badgett RC, Tanaka DV, Hunt DK, et al. Can moderate chronic obstructive pulmonary disease be diagnosed by historical and physical findings alone? Am J Med 1993; 94: 188-196.

5. Weitzenblum E, Apprill M, Oswald M, Chaouat A, Imbs J-L. Pulmonary haemodynamics in patients with chronic obstructive pulmonary disease before and during an episode of peripheral oedema. Chest 1994; 105: 13771382.

6. Quanjer PH, Tammeling GJ, Cotes JE, Pedersen OF, Peslin R, Yernault J-C. Lung volumes and forced ventilatory flows. Eur Respir J 1993; 6 (Suppl. 16): 5-40.

7. Eliasson O, Degraff AC. The use of criteria for reversibility and obstruction to define patient groups for bronchodilator trials. Am Rev Respir Dis 1985; 132: 858-864.

8. Guyatt GH, Townsend M, Nogradi S, Pugsley SO, Keller JL, Newhouse MT. Acute response to bronchodilator: an imperfect guide for bronchodilator therapy in chronic airflow limitation. Arch Intern Med 1988; 148: 1949-1952.

9. Callahan CM, Dittus RS, Katz BP. Oral corticosteroid therapy for patients with stable chronic obstructive pulmonary disease. Ann Intern Med 1991; 114: 216-223.

10. Rochester DF, Braun NMT. Determinants of maximal inspiratory pressure in chronic obstructive pulmonary disease. Am Rev Respir Dis 1985; 132: 42-47.

11. McNicol MW, Campbell EJM. Severity of respiratory failure: arterial blood gases in untreated patients. Lancet 1965; i: 336-341.

12. Knox AJ, Morrison JFJ, Muers MF. Reproducibility of walking test results in chronic obstructive airways disease. Thorax 1988; 43: 388-392.

13. Burrows B, Lebowitz MD, Camilli AE, Knudson RJ. Longitudinal changes in forced expiratory volume in one second in adults. Am Rev Respir Dis 1986; 133: 974-980.

14. Weitzenblum E, Hirth C, Ducolone A, Mirhom R, Rasaholinjanahary J, Ehrhart M. Prognostic value of pulmonary artery pressure in chronic obstructive pulmonary disease. Thorax 1981; 36: 752-758.

15. Tramarin R, Torbicki A, Marchandise B, Laaban JP, Morpurgo M. Doppler echocardiographic evaluation of pulmonary artery pressure in chronic obstructive pulmonary disease: a European multicentre study. Eur Heart J 1991; 12: 103-111.

16. Fletcher E, Luckett R, Miller T, Costarangos C, Kutka $\mathrm{N}$, Fletcher J. Pulmonary vascular hemodynamics in chronic lung disease patients with and without oxyhemoglobin desaturation during sleep. Chest 1989; 95: 157-166.

17. Pratt PC. Role of conventional chest radiography in diagnosis and exclusion of emphysema. Am Med J 1987; 82: 998-1006.

18. Thurlbeck WM, Simon G. Radiographic appearance of the chest in emphysema. Am J Roengenol 1978; 130: 429-440.

19. Chetty KG, Brown SE, Light RW. Identification of pulmonary hypertension in chronic obstructive pulmonary disease from routine chest radiographs. Am Rev Respir Dis 1982; 126: 338-341.

20. Gould GA, MacNee W, McLean A, et al. CT measurements of lung density in life can quantitate distal airspace enlargement: an essential defining feature of human emphysema. Am Rev Respir Dis 1988; 137: 380-392.

21. Klein JS, Gamsu G, Webb WR, Golden JA, Muller ML. High-resolution CT diagnosis of emphysema in symptomatic patients with normal chest radiographs and isolated low diffusing capacity. Radiology 1992; 182: 817-821.

22. Guest PJ, Hansel DM. High-resolution computed tomography (HRCT) in emphysema associated with $\alpha_{1}$-antitrypsin deficiency. Clin Radiol 1992; 45: 260-266.

23. Jones PW. Measurement of quality of life in chronic obstructive lung disease. Eur Respir Rev 1991; 1: 445-453.

\section{Treatment}

\section{Introduction}

The goals of treatment in COPD are to prevent symptoms and recurrent exacerbations and to preserve optimal lung function both in the short- and long-term; thus, improving activities of daily living and enhancing the quality of life. However, few therapeutic options have been shown to prevent COPD or to stop the accelerated loss of lung function. The main preventive measure is smoking cessation.

Although COPD is largely an irreversible, progressive disease, a policy of minimal therapeutic intervention is not justified. Results of treatment should focus not only on changes in lung function but also on quality of life. 
A reliable scientific basis in controlled clinical studies is lacking for many pharmacological and rehabilitation therapies. Therefore, an empirical approach based on current information is presented here and in the flowcharts that follow.

\section{Cessation of smoking}

A high priority should be given to the primary prevention of COPD by reducing the number of people who start to smoke. For patients who have already developed COPD, smoking cessation reduces the rate of lung function decline [1]. There is a small increase in FEV1 initially in some patients. Approximately one third of patients are able to give up smoking with support; in the remainder, nicotine addiction and other factors make reduction or cessation difficult.

Most smokers have tried to stop at some time and repeated attempts are often needed to achieve success. Smoking cessation should be seen as a constant target and patients may need to be encouraged to go through the cycle of contemplation of cessation, positive action and relapse many times. Various degrees of support are possible from simple advice to pharmacological and behavioural therapy. Many interventions show impressive short-term results but poorer sustained cessation rates of up to $30 \%$.

The most successful method of cessation is to quit abruptly, although the relapse rate is high. Gradual withdrawal may be successful in reducing total tobacco consumption but is generally unsuccessful in achieving cessation. Heavy smokers and those with multiple previous attempts are less likely to be successful.

The first stage is to provide an explanation of the effects of smoking, and the benefits of stopping, and to give encouragement to quit. A minority of patients will stop smoking after simple advice, which may be more successful at the time of presentation with respiratory or other symptoms. Advice should include helpful strategies in stopping and encouragement on other healthy life style changes. If such encouragement is not successful, then the second stage is more intensive support. This may include nicotine replacement, behavioural intervention, individual or group programmes. Temporary nicotine replacement by chewing gum or transcutaneous routes [2-4] and behavioural intervention [5] have been shown to increase success rates.

Encouragement to stop smoking is an important element in all professional consultations. Health-care professionals should not smoke. Advertising bans, smoke-free hospitals and public places, health warnings, and personal example are useful ways to discourage smoking.

\section{Controlling occupational and atmospheric pollution}

Occupational exposure to environmental pollution and to irritant dusts and fumes can trigger symptoms. Continued damage leads to accelerated decline in FEV1 in patients with COPD. Protection of workers through masks and appropriate design of the workplace are essential where irritant dusts and fumes are released. Specific occupational risks need to be regulated carefully.

High levels of atmospheric pollution may exacerbate symptoms and impair function of patients with COPD $[6,7]$. Indoor and outdoor air quality can be improved through adherence to air quality guidelines [8].

\section{Antibiotics}

Pathogens may be difficult to identify in exacerbations of COPD. The most common organisms are Streptococcus pneumoniae, Haemophilus influenzae, Moraxella catarrhalis, and viruses [9]. When sputum becomes purulent, patients are treated on empirical grounds with a 7-14 day course of antibiotics [10]. Knowledge of local resistance patterns is helpful in directing empirical therapy.

Inexpensive antibiotics are sufficient in most cases. Commonly used antibiotics are amoxycillin, tetracycline derivatives, and amoxycillin/clavulanic acid. Alternative treatments include newer cephalosporins, macrolides, and quinolone antibiotics. Patients may have to keep a course of antibiotics in reserve and start treatment when symptoms suggest an infective exacerbation. There is no advantage to prophylactic or aerosolized therapy except in a few selected patients with frequently recurring infections, particularly in winter.

The incidences of Staphylococcus, resistant Haemophilus, and Streptococcus infections in exacerbations of COPD are increasing [9]. Culture of sputum in exacerbations helps determine appropriate second choices of therapy when response to initial therapy is poor.

\section{Bronchodilator therapy}

Bronchodilator drugs relax smooth muscles in the airways. Spirometric responses are not seen in all patients. Even without spirometric changes, however, improvement in symptoms and functional capacity can occur [11]. There are three groups of suitable drugs: $\beta_{2}$-agonists, anticholinergic drugs, and methylxanthines.

The inhaled route of drug delivery results in fewer adverse effects. It is available for $\beta_{2}$-agonists and anticholinergic drugs, as well as corticosteroids. Many devices are available, including metered-dose inhalers with or without large-volume spacer attachments, breath-actuated metered-dose inhalers, and dry-powder inhalers. Most patients can be taught to use the inhaled route. The technique should be taught at the first prescription and checked periodically [12]. During acute exacerbations, some breathless patients may find it easier to use a nebulizer. Otherwise a good response can be achieved with spacers and dry-powder devices.

$\beta_{2}$-agonists. $\beta_{2}$-agonists are best given by inhalation but may also be administered orally and parenterally. Shortacting agents produce bronchodilatation within minutes, reaching a peak at $15-30 \mathrm{~min}$. The effect lasts $4-5 \mathrm{~h}$. 
$\beta_{2}$-agonists have been shown, in the laboratory, to protect against acute airway challenge [13]. This effect might be relevant clinically in certain situations, such as exposure to cold air. With prolonged use of $\beta_{2}$-agonists, there may be a small decrease in the acute bronchodilator effect [14].

Long-acting inhaled or oral $\beta_{2}$-agonists provide an alternative, especially for patients with night-time or early morning symptoms. However, adequate studies of longacting inhaled $\beta_{2}$-agonists in COPD are not yet available.

In acute exacerbations, there is no consistent evidence of a difference between high doses of $\beta_{2}$-agonists and anticholinergics, or an additive effect from combining the two drug classes [15]. $\beta_{2}$-agonists may cause a fall in $\mathrm{Pa}, \mathrm{O}_{2}$ due to pulmonary vascular effects, which do not occur with anticholinergic agents [16]. The intravenous route offers no advantage in most acute exacerbations.

Anticholinergic drugs. The onset of action of anticholinergic agents is slower than that of $\beta_{2}$-agonists, reaching a maximum in 30-90 min and lasting $4-6 \mathrm{~h}$ for ipratropium and 6-8 h for oxitropium. Anticholinergic agents are more effective in COPD than in asthma. Comparisons with $\beta_{2}$-agonists depend on the doses given. At submaximal doses combinations of anticholinergics and $\beta_{2}$-agonists will produce an additive effect $[16,17]$. There are individual differences in response which mean that it is worth switching between $\beta_{2}$-agonists and anticholinergics, even if the response to the first drug is poor [18]. Results at higher doses, often with theophylline present, suggest that the maximal effects are probably equivalent $[19,20]$, although some studies have found further improvement with anticholinergic agents above the maximal $\beta_{2}$-agonist effect $[21,22]$.

No evidence has been found of tolerance to anticholinergic drugs during chronic therapy [13]. There are few adverse effects. Some patients find the taste unpleasant and the commonest reported side-effect is cough. Early concerns about a decrease in mucociliary clearance have not been substantiated. There are no effects on urine flow or pupil size at normal or high doses, except when an ill-fitting mask of a nebulizer allows direct administration into the eye.

Methylxanthines. Theophylline is given orally, and aminophylline can be administered either orally or intravenously. These drugs have comparable or less bronchodilator effect than $\beta_{2}$-agonists or anticholinergic agents $[23,24]$. Methylxanthines have other effects, such as systemic and pulmonary vascular dilatation, increased salt and water excretion, and central nervous system stimulation. There is also an effect on respiratory muscles, but this is unlikely to be significant at usual therapeutic levels. Side-effects include gastric irritation, nausea, diarrhoea, headache, tremor, irritability, sleep disturbance, epileptic seizures, and cardiac arrhythmias.

Slow-release formulations can produce stable serum concentrations with once or twice-daily dosage. Therapeutic effects occur at blood levels $>5 \mu \mathrm{g} \cdot \mathrm{mL}^{-1}$, and side-effects increase considerably at levels $>15 \mu \mathrm{g} \cdot \mathrm{mL}^{-1}$. Smoking, alcohol, anticonvulsants, and rifampicin induce liver enzymes and reduce the half-life of methylxanthines. Old age, sustained fever, heart and liver failure, and drugs such as cimetidine, ciprofloxacin, and oral contraceptives increase blood levels. A change in the type of methylxanthine preparation may affect blood levels, even if the dose is unchanged. Peak blood levels should be monitored after methylxanthines are begun, every 6-12 months during therapy, after changes in dose or preparation, and with changes in the drugs or conditions mentioned above.

\section{Corticosteroids}

Corticosteroids are of great benefit in asthma, but their precise role in COPD has yet to be established. This section reflects current, common practice.

Corticosteroids can be administered intravenously, orally, and by inhalation. Oral or systemic drugs are used empirically during exacerbations and are often of benefit [25]. During an exacerbation-free period, a trial of corticosteroids, $0.4-0.6 \mathrm{mg} \cdot \mathrm{kg}^{-1}$ for 2-4 weeks, may be used to test reversibility of the airflow limitation. About $10 \%$ of patients with stable COPD will achieve an improvement in FEV1 [26].

The role of inhaled corticosteroids, which have the advantage of producing no or fewer systemic side-effects than oral corticosteroids, is much debated. Short-term studies show no or marginal beneficial effects on symptoms, lung function, and hyperresponsiveness. Three European studies are investigating the long term-effects on decline of FEV1 in patients with COPD.

Long-term oral corticosteroids should be administered only when there is a clear functional benefit. An example is an increase in postbronchodilator FEV1 of $10 \%$ predicted, and an absolute increase of at least $200 \mathrm{~mL}$, in the absence of clear benefit from inhaled corticosteroids. The dose should be reduced to the lowest effective level.

Well-known side-effects of systemic corticosteroids are obesity, muscle weakness, hypertension, psychiatric disorders, diabetes mellitus, osteoporosis, skin thinning, and bruising. The risks of osteoporosis and skin thinning with inhaled corticosteroid doses $>1,000 \mu \mathrm{g} \cdot$ day $^{-1}$ are currently under investigation. Two other side-effects, oral candidiasis and hoarseness, can be minimized by using large-volume spacers and by rinsing the mouth.

\section{Mucolytic and antioxidant agents}

In COPD, mucus is generally copious and tenacious, properties thought to promote infection and lung damage. If this is so, improved sputum clearance might reduce symptoms and the loss of lung function. Two types of drugs are used: mucolytics, which contain substances that enhance breakdown of mucoproteins; and mucoregulators, which reduce viscosity by altering sialomucin synthesis. These drugs are given orally or parenterally; acetylcysteine and ambroxol can also be administered by nebulization. 
There is no evidence to support prescription of these agents in acute exacerbations. A few long-term studies have suggested reduction in symptoms and the number of exacerbations. In a 6 month study, acetylcysteine was shown to reduce the frequency of acute exacerbations [27]. Appropriate assessment tools and prospective studies that include decay of FEV1, symptoms and quality of life as end parameters are needed. Widespread use of these agents cannot be recommended on the present evidence.

\section{Respiratory stimulants}

The use of respiratory stimulants varies markedly among European countries. Their role has not been established. Doxapram may have a positive effect during exacerbations of respiratory failure, but noninvasive supportive ventilation may prove to be a better alternative [28].

Oral almitrine bismesylate can improve oxygen tension to a similar degree as does a small increase in inspired oxygen. At the doses used originally, many side effects occurred, particularly peripheral neuropathy. There is no evidence of improved survival with almitrine, but there is with oxygen therapy. Other respiratory stimulants have not been shown to be effective, although theophylline can improve nocturnal dips in oxygen saturation [29]. On present evidence, respiratory stimulants are not recommended for patients with COPD.

\section{Other unproven or research agents}

Sodium cromoglycate, nedocromil sodium, and ketotifen have not been found to be effective in COPD. Calcium antagonists have some bronchodilator activity but have no clear therapeutic role. Antiprotease therapy is not recommended at present; it is under investigation as a replacement for $\alpha_{1}$-antitrypsin deficiency.

\section{Vaccination against pneumonia and influenza}

Pneumococcal vaccination (containing polysaccharides of 23 of the most virulent serotypes) is used in many countries. To date, there is insufficient information for its general recommendation. If given, vaccination should be repeated every 5-10 yrs.

Killed influenza vaccines are recommended; they should be given parenterally once each autumn. Most vaccines are "split", with the envelope having been chemically disrupted. They are usually trivalent, containing two subtypes of influenza A and one of influenza B. The strains are adjusted each year for best effectiveness. The protective effect is less in the elderly than in younger individuals, but serious illness and death are probably reduced by approximately $50 \%$ [30]. Live vaccines have the same protective effect as inactivated vaccines when they are antigenically matched [31].

Other immunomodulators are under investigation for long-term use in COPD. No recommendations can be made at this time.

\section{Treatment of cardiovascular sequelae}

When cor pulmonale develops in patients with COPD, further treatment may be necessary. Only oxygen produces specific vasodilatation for the pulmonary hypertension induced by hypoxic vasoconstriction. Use of other vasodilators is usually limited by their effects on the systemic circulation. Diuretics can reduce oedema, but should be used carefully to avoid reducing cardiac output and renal perfusion and creating electrolyte imbalance. The hypoxic myocardium is especially sensitive to agents such as digoxin, aminophylline, etc.

\section{Oxygen therapy}

Oxygen supplementation has been proven to be lifesaving during exacerbations of COPD. In addition, it increases the life expectancy of patients with chronic respiratory failure [32-34].

Oxygen in the hospital. During an acute, severe exacerbation, oxygen is usually given through a Venturi mask or nasal cannulae, or by mechanical ventilation. The goal of therapy is to raise the $\mathrm{Sa}_{\mathrm{a}} \mathrm{O}_{2}$ to $\geq 90 \%$ and/or the $P \mathrm{a}, \mathrm{O}_{2}$ to $\geq 8.0 \mathrm{kPa}(60 \mathrm{mmHg})$ without elevating the arterial carbon dioxide tension $\left(P \mathrm{a}, \mathrm{CO}_{2}\right)$ by $>1.3 \mathrm{kPa}(10$ $\mathrm{mmHg}$ ) or lowering $\mathrm{pH}$ to $<7.25$. Oxygen administration should start at a low dose $(24 \%$ by Venturi mask or 1-2 L $\cdot \mathrm{min}^{-1}$ by nasal cannulae). Arterial blood gas tensions should be monitored regularly. Oxygen doses are adjusted until the goal is accomplished.

Long-term domiciliary oxygen treatment (LTOT). Studies have shown that LTOT improves survival in patients with COPD and chronic respiratory failure [33, 34]. Criteria for LTOT are respiratory failure during a stable 3-4 week period despite optimal therapy, with $\mathrm{Pa}_{\mathrm{a}} \mathrm{O}_{2} \leq 7.3 \mathrm{kPa}$ (55 $\mathrm{mmHg}$ ), with or without hypercapnia. In some countries, the criteria are broader: $\mathrm{Pa}, \mathrm{O}_{2}$ of $7.3-7.9 \mathrm{kPa}(55-59$ $\mathrm{mmHg}$ ) in the presence of pulmonary hypertension, cor pulmonale, polycythaemia, or severe nocturnal hypoxaemia. However, LTOT is generally not prescribed for patients who continue to smoke.

A flow of $1.5-2.5 \mathrm{~L} \cdot \mathrm{min}^{-1}$ through nasal cannulae is usually adequate to achieve $\mathrm{Pa}, \mathrm{O}_{2}>8.0 \mathrm{kPa}(60 \mathrm{mmHg})$. The flow should be adjusted according to arterial blood gas tensions or oximetry results. In some countries, night-time measurements are included in the determination of dosage. The dose should be assessed at least once each year. Because a greater survival benefit has been shown with continuous administration of oxygen, LTOT should be used for as many hours as possible; the minimum recommendation is $15 \mathrm{~h} \cdot \mathrm{day}^{-1}$, including during sleep.

Nasal cannulae are usually used for LTOT. Venturi masks, however, deliver a more accurate oxygen concentration. Transtracheal oxygen through a fine percutaneous catheter should be considered for the few patients who have high oxygen demands or who prefer this route for cosmetic reasons [35]. 
Oxygen concentrators, cylinders, and liquid oxygen are available for delivering oxygen. Oxygen concentrators are the easiest mode of treatment, as they require only an electricity supply. Cylinders are too cumbersome and too expensive for LTOT. Liquid oxygen has one advantage: its additional small portable system can be used during travel and exercise. Oxygen-conserving devices (e.g. a moustache) extend the duration of cylinder and portable systems. A home oxygen care system requires careful monitoring by respiratory nurses or other domiciliary assistants. In subjects with exercise-induced hypoxaemia, oxygen supplementation may improve performance and reduces breathlessness. In end-stage COPD, short bursts of oxygen may ameliorate intractable dyspnoea, often via a placebo effect.

Home mechanical ventilation. Noninvasive ventilatory support, using either negative extrathoracic pressure or positive pressure techniques by nasal or facial mask, rests respiratory muscles and improves gas exchange. Positive pressure support is under investigation for its possible long-term beneficial effects in COPD [36]. Patients with severe nocturnal hypoxaemia or respiratory muscle weakness are the best candidates for this treatment.

\section{Treatment of dyspnoea}

In some cases, breathlessness is more severe than expected for the level of airflow limitation. Rehabilitation programmes can help achieve any reversibility of obstruction and improve muscle function. Cardiac dysfunction and anaemia may coexist, and depression and anxiety may aggravate the dyspnoea. Results regarding the effects of anxiolytic drugs are conflicting, and further studies are required.

In advanced disease, suppression of dyspnoea can be achieved only at the expense of depressed ventilation and at the risk of respiratory failure. Morphine is the most potent drug in this respect, but it carries the highest risk of respiratory depression and addiction; therefore, it should be used only in terminal stages.

\section{Rehabilitation}

Patients with advanced airflow limitation and severe dyspnoea become increasingly less mobile. Their skeletal muscles detrain, and dyspnoea and diminished exercise capacity are exacerbated. Rehabilitation programmes have been shown to increase exercise tolerance and to improve quality of life [37, 38]. An identifiable group of patients with muscle weakness may benefit from training specific muscles [39-41].

Rehabilitation uses a multidisciplinary programme of physiotherapy, muscle training, nutritional support, psychotherapy, and education.

Physiotherapy. Coughing and forced expiratory manoeuvres aid the clearance of secretions. Relaxation techniques, pursed-lip breathing, and control of breathing patterns to avoid rapid, shallow breaths may occasionally help patients to cope with acute dyspnoea.

Muscle training. General exercise reconditioning is the best mode of rehabilitation, even in patients with severe airflow limitation, if the programme is suitably modulated. Walking is generally preferred, but stair-climbing, treadmill, or cycling exercises can also be used. Patients with particularly severe muscle weakness benefit most. In those who can achieve the anaerobic threshold, physiological benefits have been demonstrated. Exercise programmes improve the quality of life through mechanisms that are not yet clear. The programme must be maintained, because benefits generally disappear rapidly if exercise is discontinued. Exercise training can be performed successfully at home [38].

The benefit of respiratory muscle training as an addition to general muscle conditioning or as an individual activity is not yet clear. Most studies indicate improved respiratory muscle function if the training load is adequately controlled. Whether the goal of training should be strength, endurance, or both is still under investigation.

Nutrition. Both obesity and loss of body mass are common features of COPD. Undernutrition is associated with respiratory muscle dysfunction and increased mortality. Nutritional intervention is important, but it is often unsuccessful. Until information is available on new avenues under investigation, it seems reasonable to recommend nutritional interventions aimed towards achieving an ideal body weight. High-carbohydrate diets and extremely high caloric intake should be avoided to reduce the risk of excess carbon dioxide production.

Psychotherapy and education. Psychosocial support and patient and family education are expected to improve quality of life. Those programmes focus on restoration of coping skills, management of stress and medical emergencies, use of medications, nutrition, general health, and social activities [42]. Patients who have a good understanding of their condition may be encouraged to discuss what they want to happen in the event that an episode of respiratory failure necessitates ventilation. Such a "living will" needs to be reviewed carefully if intensive care or ventilation is being considered.

\section{References}

1. Anthonisen NR, Connett JE, Kiley JP et al. Effects of smoking intervention and the use of an inhaled anticholinergic bronchodilator on the rate of decline of FEV1. The Lung Health Study. J Am Med Assoc 1994; 272 : 1497-1505

2. Russell MA, Stapleton JA, Feyerabend C, et al. Targetting heavy smokers in general practice: randomised controlled trial of transdermal nicotine patches. Br Med J 1993; 306: 1308-1312.

3. Tang JL, Law M, Wald N. How effective is nicotine replacement therapy in helping people to stop smoking? Br Med J 1994; 308: 21-26. 
4. Silagy C, Mant D, Fowler G, Lodge M. Meta-analysis on efficacy of nicotine replacement therapies in smoking cessation. Lancet 1994; 343: 139-142.

5. Fisher EB, Haire-Joshu D, Morgan GD, Rehberg H, Rost K. Smoking and smoking cessation. Am Rev Respir Dis 1990; 142: 702-720.

6. Xu X, Wang L. Association of indoor and outdoor particulate pollution level with chronic respiratory illness. Am Rev Respir Dis 1993; 148: 1516-1522.

7. Tashkin DP, Detels R, Simmons M, et al. The UCLA population studies of chronic obstructive pulmonary disease. XI. Impact of air pollution and smoking on annual change in forced expiratory volume in one second. Am J Respir Crit Care Med 1994; 149: 1067-1083.

8. World Health Organization. Air quality guidelines for Europe. Copenhagen, WHO Regional Office for Europe, 1987.

9. Murphy TF, Sethi S. State of the art: bacterial infection in chronic obstructive pulmonary disease. Am Rev Respir Dis 1992; 146: 1067-1083.

10. Anthonisen NR, Manfreda J, Warren J, et al. Antibiotic therapy in exacerbations of chronic obstructive pulmonary disease. Ann Intern Med 1987; 106: 196-204.

11. Hay JG, Stone, Carter J, Church S, et al. Bronchodilator reversibility, exercise performance and breathlessness in stable chronic obstructive pulmonary disease. Eur Respir $J$ 1992; 5: 659-664.

12. Siafakas NM, Bouros D. Choice of inhalation therapy in adults. Eur Respir Rev 1994; 4 (18): 78-81.

13. Bel EH, Zwinderman AH, Timmers MC, Dijkman JH, Sterk PJ. The protective effect of a $\beta_{2}$-agonist against excessive airway narrowing in response to bronchoconstrictor stimuli in asthma and chronic obstructive lung disease. Thorax 1991; 46: 9-14.

14. Tashkin DP, Ashutosh K, Bleeker ER, et al. Comparison of the anticholinergic bronchodilator ipratropium bromide with metaproterenol in chronic obstructive pulmonary disease: a 90 day multicenter study. Am J Med 1986; 81(Suppl. 5A): 81-89.

15. Karpel JP, Pesin J, Greenberg D, Gentry E. A comparison of the effects of ipratropium bromide and metaproterenol sulphate in acute exacerbations of COPD. Chest 1990; 98: 835-839.

16. Gross N, Bankwala Z. Effects of an anticholinergic bronchodilator on arterial blood gases of hypoxemic patients with chronic obstructive pulmonary disease. Am Rev Respir Dis 1987; 136: 1091-1094.

17. Bone $\mathrm{R}$, et al, for the Combivent Inhalation Aerosol Study. Combination of ipratropium and albuterol is more effective than either agent alone. Chest 1994; 105: 1411-1419.

18. Douglas NJ, Davidson I, Sudlow MF, Flenley DC. Bronchodilatation and the site of airway resistance in severe bronchitis. Thorax 1979; 34: 51-56.

19. Easton PA, Jadue C, Dhingra S, Anthonisen NR. A comparison of the bronchodilating effects of a beta ${ }_{2}$-adrenergic agent (albuterol) and an anticholinergic agent (ipratropium bromide), given by aerosol alone or in sequence. N Engl J Med 1986; 315: 735-739.

20. Karpel JF. Bronchodilator responses to anticholinergic and beta-adrenergic agents in acute and stable COPD. Chest 1991; 99: 871-876.

21. Gross NJ, Skorodin MS. Role of the parasympathetic system in airway obstruction due to emphysema. $N \mathrm{Engl}$ J Med 1984; 311: 421-425.

22. Brown IG, Chan CS, Kelly CA, Dent AG, Zimmerman $\mathrm{PV}$. Assessment of the clinical usefulness of nebulised ipratropium bromide in patients with chronic airflow limitation. Thorax 1984; 39: 272-276.

23. Guyatt GH, Townsend M, Pugsley SO, et al. Bronchodilators in chronic air-flow limitation. Am Rev Respir Dis 1987; 135: 1069-1074.

24. Jenne JW. What role for theophylline therapy? Thorax 1994; 49: 97-100.

25. Albert RK, Martin TR, Lewis SW. Controlled clinical trial of methylprednisolone in patients with chronic bronchitis and acute respiratory insufficiency. Ann Intern Med 1980; 92: 753-758.

26. Callahan C, Dittus RS, Katz BP. Oral corticosteroid therapy for patients with stable chronic obstructive pulmonary disease: a meta-analysis. Ann Intern Med 1991; 114: 216-223.

27. Multicenter Study Group. Long-term oral acetylcysteine in chronic bronchitis, a double-blind controlled study. Eur J Respir Dis 1980; 61 (Suppl. 111): 93-108.

28. Bott J, Carroll MP, Conway JH, et al. Randomised controlled trial of nasal ventilation in acute ventilatory failure due to chronic obstructive airways disease. Lancet 1993; 341: 1555-1557.

29. Berry RB, Desa MM, Branum JP, Light RW. Effect of theophylline on sleep and sleep-disordered breathing in patients with chronic obstructive pulmonary disease. Am Rev Respir Dis 1991; 143: 245-250.

30. Nichol KL, Margolis KL, Wuorenma J, von Sternberg T. The efficacy and cost effectiveness of vaccination against influenza among elderly persons living in the community. N Engl J Med 1994; 331: 778-784.

31. Edwards KM, Dupont WD, Westrich MK, Plummer WD Jr, Palmer PS, WrighL PF. A randomised controlled trial of cold-adapted and inactivated vaccines for the prevention of influenza A viruses. J Infect Dis 1994; 169: 68-76.

32. Campbell EJM. Management of respiratory failure. $\mathrm{Br}$ Med J 1964; 2: 1328-1339.

33. Nocturnal Oxygen Therapy Trial Group. Continuous or nocturnal oxygen therapy in hypoxemic chronic obstructive lung disease: a clinical trial. Ann Intern Med 1980; 391-398.

34. Medical Research Council Working Party. Long-term domiciliary oxygen in chronic hypoxic cor pulmonale complicating chronic bronchitis and emphysema. Lancet 1981; i: 681-686.

35. Couser JI Jr, Make BJ. Transtracheal oxygen decreases inspired minute ventilation. Am Rev Respir Dis 1989; 139: 627-631.

36. Ambrosino M, Nava S, Bertone P, Fracchia C, Rampulla C. Physiologic evaluation of pressure support ventilation by nasal mask in patients with stable COPD. Chest 1992; 101: 385-391.

37. Goldstein RS, Gort EH, Stubbing D, Avendano MA, Guyatt GH. Randomised controlled trial of respiratory rehabilitation. Lancet 1994; 344: 1394-1397.

38. Wijkstra PJ, Van Altena R, Kraan J, Otten V, Postma DS, Koeter GH. Quality of life in patients with chronic obstructive pulmonary disease improves after rehabilitation at home. Eur Respir J 1994; 7: 269-273.

39. Begin P, Grassino A. Inspiratory muscle dysfunction and chronic hypercapnia in chronic obstructive pulmonary disease. Am Rev Respir Dis 1991; 143: 905-912.

40. Donner CF, Howard P. Pulmonary rehabilitation in chronic obstructive pulmonary disease (COPD) with recommendations. Eur Respir J 1992; 5: 226-275.

41. Smith K, Cook D, Guyatt GH, Madhaven J, Oxman AD. Respiratory muscle training in chronic airflow limitation: 
a meta-analysis. Am Rev Respir Dis 1992; 145: 533539.

42. Kaplan R, Eakin EG, Ries AL. Psychosocial issues in the rehabilitation of patients with chronic obstructive pulmonary disease. In: Casaburi R, Petty T, eds. Principles and practice of pulmonary rehabilitation. Philadelphia, WB Saunders Co., 1993; pp. 351-365.

\section{Management}

\section{Stable COPD}

Aims of management. The aims of management of stable COPD are: 1) to improve symptoms and quality of life; 2) to reduce the decline of lung function; 3) to prevent and treat complications; 4) to increase survival with maintained quality of life; and 5) to avoid or minimize adverse effects of treatment.

The underlying damage in COPD is largely irreversible. Despite the irreversibility, clinicians should maintain a positive approach to the management of COPD, as symptoms and quality of life of the patient can be substantially improved. However, primary prevention of the condition is of utmost importance. The most important tactic, especially for younger subjects, is to stop smoking.

Some areas of management remain controversial and need further research. In particular, the role of inhaled corticosteroids in reducing the rate of decline of lung function, as well as the roles of antioxidants and mucolytics, need additional study. Monitoring of patients in early stages of the disease to detect a group having an accelerated decline in lung function is another important area for further research.

Algorithms. The following guidelines for the management of stable COPD assume that the correct diagnosis has been made. An alternative diagnosis may need to be considered at various points. A diagnosis of asthma necessitates consideration of the consensus guidelines for asthma [1-4]. Alternative diagnoses should be considered when the degree of breathlessness is out of proportion to the degree of airflow limitation.

Flow charts have been designed according to the severity of airflow limitation, based on the reduction in FEV1. For convenience, two algorithms are proposed for use in stable COPD: one for mild disease (fig. 1) and the other for moderate to severe disease (fig. 2). The severity of airflow limitation has been divided into two categories: mild (fig 1) and moderate to severe (fig. 2). The distinction is based on the reduction in FEV1.

The guidelines offer alternative therapies in some situations where multiple treatments having similar effects are available or scientific evidence is lacking. In these cases, preference of the patient or the doctor may influence the selection. Precise instructions on drug choice within a pharmacological group have not been included in the guidelines. Notes to the flowcharts, indicated by circled numbers, appear after figure 2.

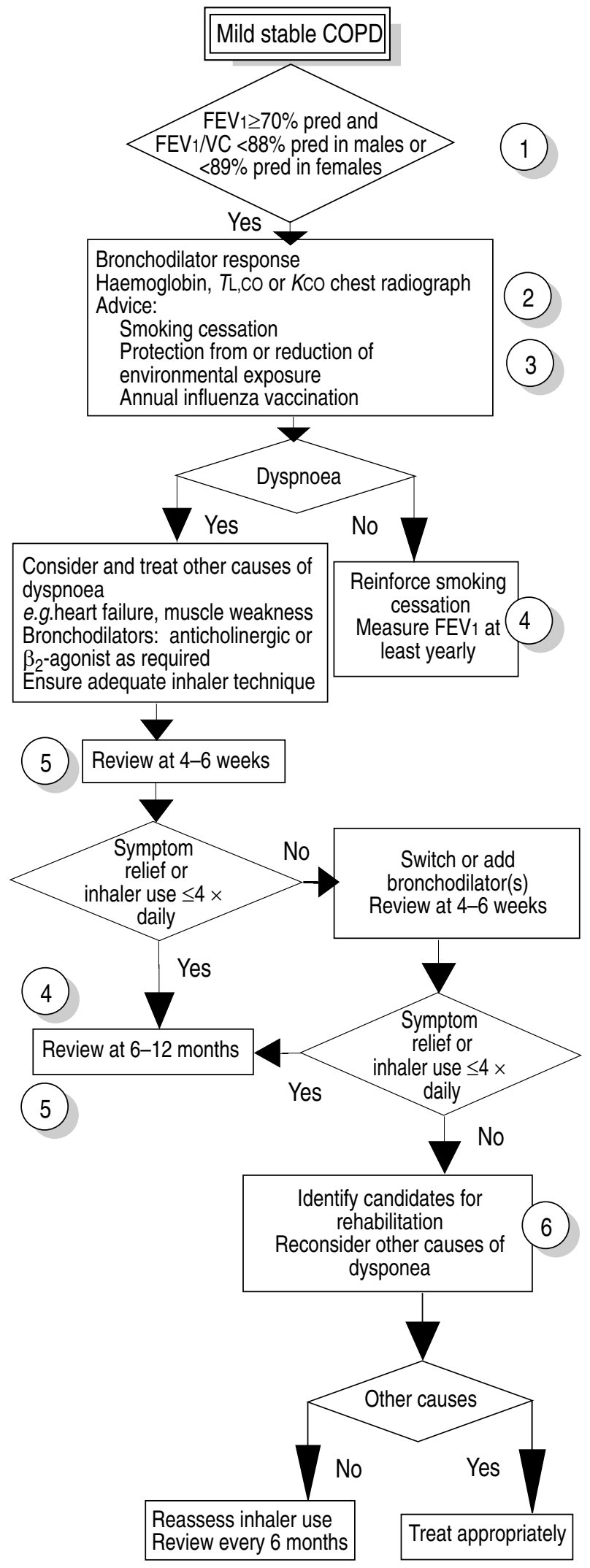

Fig. 1 - Flow chart designed for use in patients with mild, stable COPD. For explanation of circled number see notes after figure 2 . COPD: chronic obstructive pulmonary disease; FEV1: forced expiratory volume in one second; \% pred: percentage of predicted value; VC: vital capacity; TL,CO: transfer factor of the lungs for carbon monoxide; KCO: carbon monoxide transfer coefficient. 

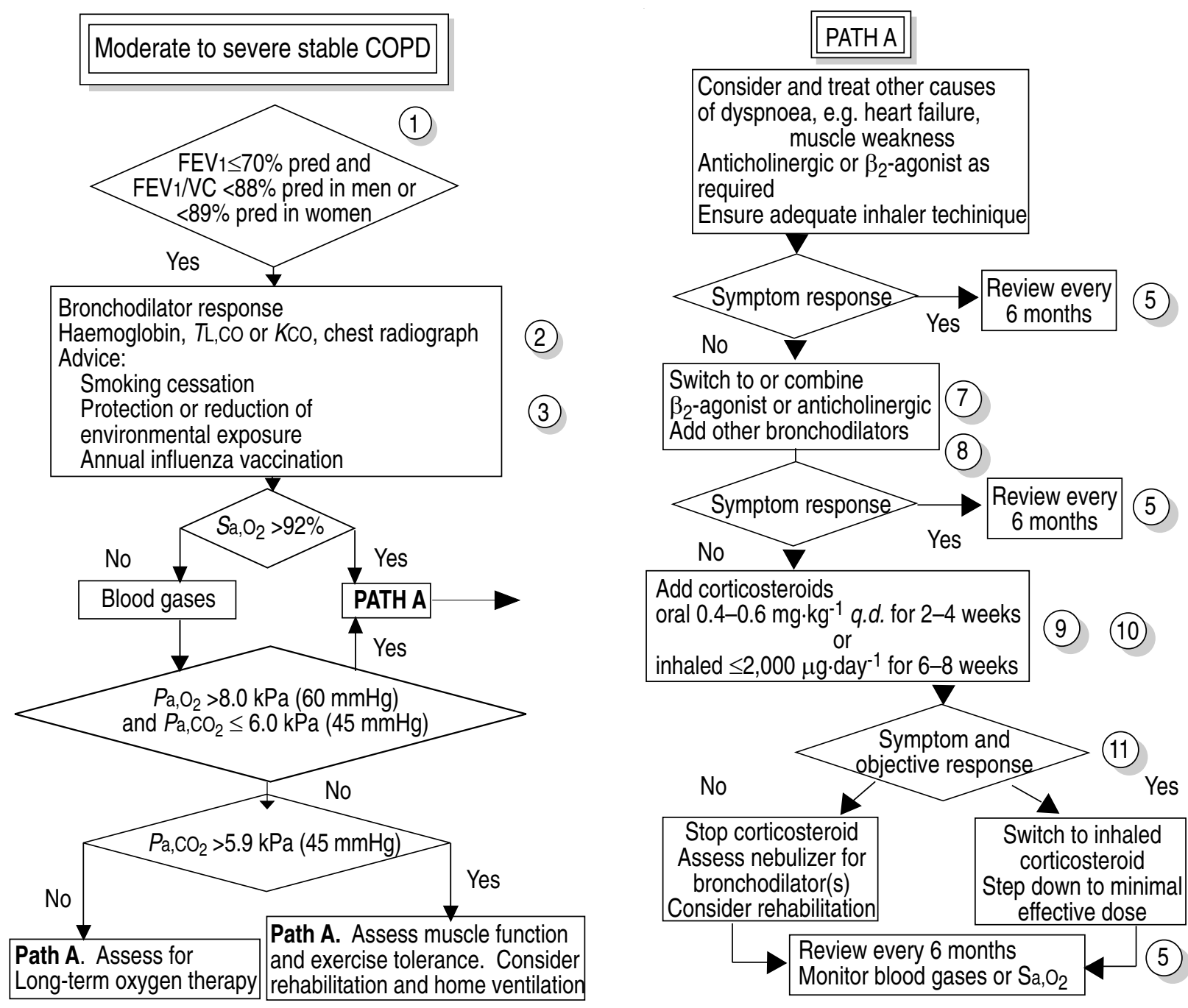

Fig. 2. - Flow chart designed for use in patients with moderate to severe, stable COPD. $S_{a}, O_{2}:$ arterial oxygen saturation; $P$ a, $\mathrm{O}_{2}$ : arterial oxygen tension; $\mathrm{Pa}_{\mathrm{a}, \mathrm{CO}_{2}}$ : arterial carbon dioxide tension. For explanation of circled numbers see notes below.

\section{Notes}

(1) $\mathrm{FEV} 1 / \mathrm{VC} 11.7 \%$ below predicted in men and $10.7 \%$ below predicted in women are 1.64 residual standard deviations below predicted.

(2) If asthma is suspected (FEV1 reversibility $>10 \%$ predicted after $\beta_{2}$-agonists and/or anticholinergic), then measure peak expiratory flow (PEF) and perform a bronchial challenge test to determine the concentration of histamine or methacholine needed to provoke a $20 \%$ reduction (PC20) in FEV1. Follow the asthma guidelines if: a) peak flow diurnal variation $>15 \%$ over 2 weeks (PEF variation=highest $\mathrm{PEF}$ of the day-lowest $\mathrm{PEF} /$ mean of highest and lowest PEF; and b) $\mathrm{PC} 20<2 \mathrm{mg} \cdot \mathrm{mL}^{-1}$ histamine or methacholine.

(3) If emphysema is suspected, measure $\alpha_{1}$-antitrypsin and consider computed tomography (CT) scanning.

(4) A fast rate of decline in FEV1 $\left(>50 \mathrm{~mL} \cdot \mathrm{yr}^{-1}\right)$ is an indication to consider inhaled corticosteroids.

5) At review, check dose and frequency of medications, symptom relief, inhaler technique, smoking status (reinforce cessation), FEV1, and VC.

6 Assess exercise capacity and respiratory muscle function to identify those patients who might benefit from general body or respiratory muscle training.

(7) For some patients, the frequency of dosing may need to be increased; for others, the dose may need to be doubled.

(8) Prescribe theophylline (adjusted doses to peak serum level of 5-15 $\mu \mathrm{g} \cdot \mathrm{L}^{-1}$ ). If theophylline is not tolerated, consider long-acting oral or inhaled $\beta_{2}$-agonists.

(9) If long-term oral corticosteroids are used, protection from osteoporosis should be considered (calcium and vitamin D, hormone replacement, diphosphonates). Inhaled corticosteroids should be used in addition to minimize the oral dose.

(10) For high doses of inhaled corticosteroids $\left(\geq 1,000 \mu \mathrm{g} \cdot\right.$ day $\left.^{-1}\right)$, a large-volume spacer or dry-powder system should be used.

(11) Objective response: FEV1 improvement $\geq 10 \%$ predicted and/or $>200 \mathrm{ml}$. 
Table 3. - Causes of acute exacerbation of COPD

\section{Primary}

Infection of the tracheobronchial tree (often viral)

Secondary

Pneumonia

Right or left heart failure or arrhythmias

Pulmonary embolism

Spontaneous pneumothorax

Inappropriate oxygen administration

Drugs (hypnotics, tranquillisers, diuretics, etc.)

Metabolic diseases (diabetes, electrolyte disturbances, etc.)

Poor nutritional stage

Other diseases (gastrointestinal bleeding, etc.)

End-stage respiratory disease (fatigue of respiratory muscles, etc.)

\begin{tabular}{|c|c|}
\hline \multicolumn{2}{|c|}{$\begin{array}{l}\text { Criteria and measurements } \\
\text { for severe }{ }^{\star} \text { acute exacerbation }\end{array}$} \\
\hline & \\
\hline \multicolumn{2}{|c|}{$\begin{array}{l}\text { If in doubt } \\
\text { always assess in hospital }\end{array}$} \\
\hline \multicolumn{2}{|r|}{$\downarrow$} \\
\hline $\begin{array}{l}\text { History: } \\
\text { Symptoms: } \\
\text { Signs: }\end{array}$ & $\begin{array}{l}\text { Previous condition } \\
\text { Cough } \uparrow \sqrt{\checkmark} \\
\text { Sputum i } \Omega \\
\odot \text { Dyspnoea at rest } 1 \\
\text { Temperature }>38.5^{\circ} \mathrm{C} \\
\text { Oedema } \\
\odot \text { Respiratory rate }>25 \text { breaths } \cdot \mathrm{min}^{-1} \\
\odot \text { Heart rate }>110 \text { beats } \cdot \mathrm{min}^{-1} \\
\odot \text { Worsening cyanosis } \\
\odot \text { Use of accessory muscles } \\
\bullet \text { Loss of alertness } \\
\text { PEF }<100 \mathrm{~L} \cdot \mathrm{min}^{-1}\end{array}$ \\
\hline Measurements i & $\begin{array}{l}\text { hospital: } \\
\text { FEV } 1<1 \mathrm{~L} \\
\text { Breathing air: } \\
\mathrm{Pa}_{2} \mathrm{O}_{2}<8.0 \mathrm{kPa}(60 \mathrm{mmHg}), \mathrm{Sa}_{2} \mathrm{O}_{2}<90 \% \\
\mathrm{~Pa}_{2} \mathrm{CO}_{2} \geq 6.0 \mathrm{kPa}(45 \mathrm{mmHg}) \\
\text { Chest radiograph } \\
\text { White blood cell count } \geq 12,000 \\
\text { Sputum stain/culture } \\
\text { Biochemistry (electrolytes, urea, } \\
\quad \text { glucose, etc.) } \\
\text { Electrocardiogram }\end{array}$ \\
\hline & Life-threatening \\
\hline $\begin{array}{l}\text { Symptoms: } \\
\text { Measurement: }\end{array}$ & $\begin{array}{l}\text { Respiratory or cardiac arrest } \\
\text { Confusion or coma } \\
\text { Breathing air: } \\
\mathrm{Pa}_{2} \mathrm{O}_{2}<6.7 \mathrm{kPa}(50 \mathrm{mmHg}) \\
\mathrm{Pa}_{2} \mathrm{CO}_{2} \geq 9.3 \mathrm{kPa}(70 \mathrm{mmHg}) \\
\mathrm{pH}<7.3\end{array}$ \\
\hline
\end{tabular}

Fig. 3. - Criteria for management of severe, acute exacerbations of COPD. *: otherwise considered "Mild $\Rightarrow$ Home management" (see fig. 4). Clinical judgement of the physician is important. Significant parameters are the loss of alertness $(\bullet)$ and combination of conditions indicated by the symbol $\odot$. PEF: peak expiratory flow. For further abbreviations see legends to figures 1 and 2 .

\section{Exacerbations}

The proper management of an exacerbation of COPD requires knowledge of the usual causes of exacerbations (table 3). The previous condition of the patient must also be considered.

Although most exacerbations are mild and can be treated on an out-patient basis (home care), severe events should usually be evaluated in the Emergency Department of a hospital, so that the patient can be admitted if necessary. If the severity of an episode is in doubt, the assessment should take place in the hospital. In a very severe, life-threatening episode, direct admission into the Intensive Care Unit is indicated. Criteria for assessment of severity are presented in figure 3.

Home management. The usual cause of an exacerbation is infection, often viral. The goals of management are: 1) to treat bacterial infection if present; 2) to remove excess secretions; 3) to increase maximum airflow; and 4) to improve respiratory muscle strength.

Because of the broad range of clinical symptoms and signs, an individualized approach to treatment is needed. Figure 4 may be used as a guideline.

Hospital management. The main goals of hospital management of an exacerbation of COPD are: 1) to evaluate the severity, including life-threatening conditions; 2) to identify the cause of the exacerbation; 3) to provide controlled oxygenation; and 4) to return the patient to the best previous condition.

Figure 5 is a chart of hospital management. Because there are many causes of acute on chronic respiratory failure, this figure provides only guidelines for a general approach. Treatment depends on the degree of severity and should be adapted to the features of each individual case.

\section{Special considerations}

\section{Air travel}

Patients with COPD who have chronic hypoxaemia or borderline $\mathrm{Pa}_{2} \mathrm{O}_{2}(\leq 9.3 \mathrm{kPa}(70 \mathrm{mmHg}))$ at rest, at sea level, may become more hypoxaemic during air travel. The clinical significance of short episodes of worsened hypoxaemia is largely unknown. When a long trip is planned, the risk may be estimated by simulating in the laboratory the partial pressure of inspired oxygen that will occur during the flight. Another approach is to try to predict the risk from the patient's blood gas tensions. These tests can also determine the amount of supplemental oxygen necessary.

Relative contraindications to air travel include current bronchospasm, severe dyspnoea, severe anaemia, unstable coexisting cardiac disorders, impaired pulmonary function, with $\mathrm{Pa}_{\mathrm{a}} \mathrm{CO}_{2} \geq 6.7 \mathrm{kPa}(50 \mathrm{mmHg}), P \mathrm{a}, \mathrm{O}_{2} \leq 6.7$ $\mathrm{kPa}(50 \mathrm{mmHg}), T \mathrm{~L}, \mathrm{CO} \leq 50 \%$ of predicted, and $\mathrm{VC} \leq 50 \%$ of predicted. Conditions adversely affected by pressure changes (e.g. noncommunicating lung cysts, pneumothorax, or pneumomediastinum) may also contraindicate air travel $[6,7]$. 


\section{Mild exacerbation (home management)}

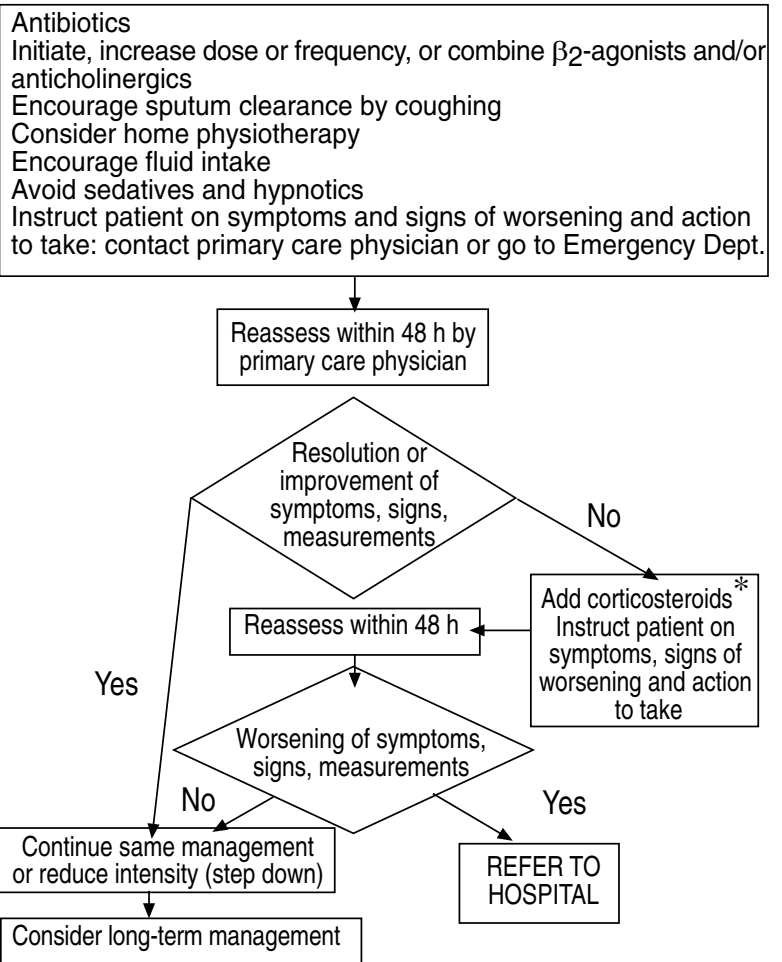

Fig. 4. - Guidelines for treatment of mild exacerbations of COPD. *: consider a short course of corticosteroids $\left(0.4-0.6 \mathrm{mg} \cdot \mathrm{kg}^{-1}\right.$ daily), from the beginning if marked wheeze is present.

\section{Surgical treatment}

In selected patients with unilateral or even bilateral large air cysts, bullectomy via thoracostomy or sternotomy can result in improved lung function (i.e. an increase in VC) and exercise tolerance. Predictors of success include demonstration on CT of collapsed pulmonary parenchyma beneath the bullae and persistence of zones without or with only small amounts of emphysema, as well as the value of transfer factor and $\mathrm{Pa}_{\mathrm{a}} \mathrm{CO}_{2}$. Recent developments in thoracoscopic surgery, with use of a laser, if necessary, facilitate the operation. Thoracoscopic surgery may replace segmentectomy for resection of a peripheral carcinoma in patients with severely compromised lung function [8].

Patients $<65$ yrs of age who have very poor exercise tolerance and poor lung function $(\mathrm{FEV} 1<25 \%$ predicted, $P$ a, $\mathrm{O}_{2}<7.5 \mathrm{kPa}(56 \mathrm{mmHg})$ and $P \mathrm{a}, \mathrm{CO}_{2}>6.5 \mathrm{kPa}(49$ $\mathrm{mmHg}$ ) will benefit from double or single lung transplantation. The latter is contraindicated in patients with chronic bronchial infection or bronchiectasis in the remaining lung. Long-term survival, which is approximately $50 \%$ at $5 \mathrm{yrs}$, has to be balanced with the individual's prognosis, a difficult task. Although posttransplantation exercise tolerance will improve, close follow-up is necessary [9-12].

\section{Compliance and education}

Compliance, or adherence to medical advice, has unfortunately been considered an unimportant aspect of clinical research in patients with chronic diseases, such as

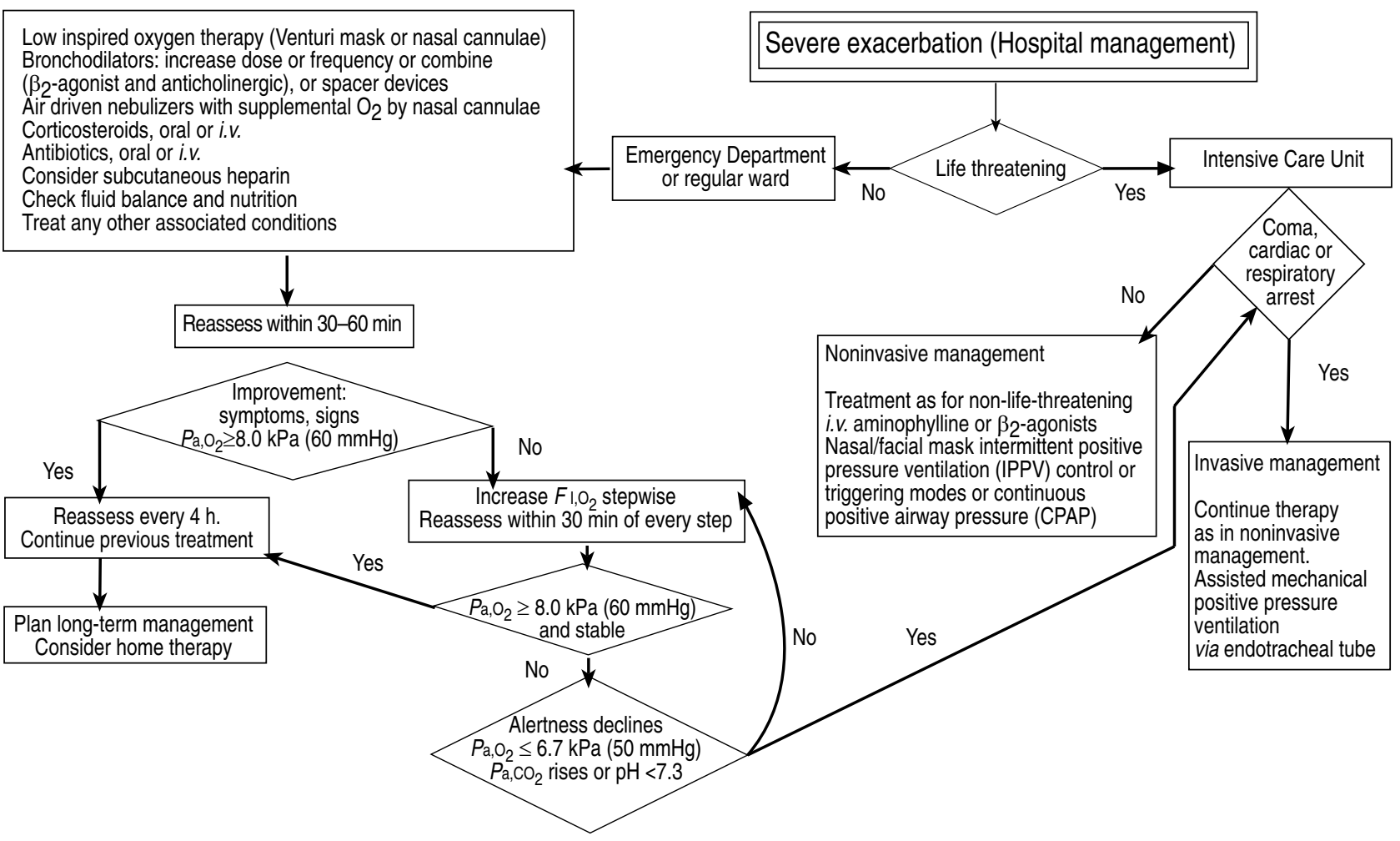

Fig. 5. - Guidelines for hospital management of severe exacerbations of COPD. $F_{\mathrm{I}, \mathrm{O}_{2}}$ : fractional inspiratory oxygen. For further abbreviations see legend to figures 1 and 2 . 
COPD. Compliance assessments have relied mainly on self-reporting, and poor recall or a desire to please may affect the results. Some objective methods are available, however, including microprocessing devices attached to inhalers and measurement of theophylline plasma levels, carbon monoxide levels in expired air, or cotinine levels in saliva or urine.

Educational programmes for COPD patients have not been as actively promoted as programmes for asthma patients. Single-topic programmes are available (e.g. smoking cessation, long-term oxygen therapy, rehabilitation), but integrated educational materials incorporating all aspects of the management approach are lacking. Educational programmes should not aim solely to improve knowledge about the disease process and its treatment, but should also be directed at changing the patient's behaviour, which could improve the quality of life. A partnership approach should be developed, encouraging active involvement by patients, their families, and healthcare workers.

\section{Future research}

Pathophysiology. Cigarette smokers, especially those with airflow limitation, have more neutrophils, lymphocytes and activated macrophages in their airways and airspaces than nonsmokers. The inflammatory process in the small airways includes an increased number of lymphocytes and mononuclear cells, increased connective tissue deposition, epithelial metaplasia, and ulceration in the airway wall. Future research is expected to better delineate the role of cytokines, the mechanisms governing chemotaxis, adhesion, and diapedesis of neutrophils and lymphocytes in the airway, and the roles of oxidantantioxidant and protease-antiprotease balances. New therapeutic modalities might follow. Genetic studies on COPD may also be helpful.

Epidemiology. Areas for future epidemiological research include: 1) standardized statistics for morbidity, mortality, and socioeconomic status in COPD for all of Europe; 2) promotion of routine use of lung function tests in symptomatic patients with lung disease; 3) surveillance of smokers and others with increased risks of COPD; 4) active involvement of chest physicians, general practitioners, and other health care workers in smoking cessation; 5) understanding of the relationship between air pollution and COPD; 6) correlation of occupational exposure and COPD, particularly the effect of cessation of exposure; 7) identification of biological markers of increased susceptibility to COPD; and 8) discovery of any genetic determinants of COPD.

Clinical benefits of treatment. Major ongoing studies (the United States National Institutes of Health Lung Health Study and European Respiratory Society Study on COPD (EUROSCOP)) are looking at the rate of change in FEV1 as the major outcome. For the individual patient, however, improvement in the quality of life and decreases in symptoms and exacerbations are the desired outcomes. All interventions should focus not only on objective changes but also on quality-of-life changes, which have a major impact on everyday life. Further studies are needed to evaluate home mechanical ventilation, the various modes of rehabilitation, and, most importantly, education of the patient and family. In addition, governments need cost-benefit analyses.

\section{References}

1. Guidelines for the management of asthma in adults. Chronic persistent asthma. Statement by the British Thoracic Society, Research Unit of the Royal College of Physicians of London, King's Fund Centre, National Asthma Campaign. Br Med J 1990; 301: 651-653.

2. Guidelines for the management of asthma in adults. Acute severe asthma. Statement by the British Thoracic Society, Research Unit of the Royal College of Physicians of London, King's Fund Centre, National Asthma Campaign. Br Med J 1990; 301: 797-800.

3. Hargreave FE, Dolovich J, Newhouse MT. The assessment and treatment of asthma: a conference report. $J$ Allergy Clin Immunol 1990; 85: 1098-1111.

4. International Consensus Report on Diagnosis and treatment of Asthma. National Heart, Lung and Blood Institute. National Institutes of Health, Bethesda, Maryland, 1992.

5. Quanjer PH, Tammeling GJ, Cotes JE, Pedersen OF, Peslin R, Yernault J-C. Lung volumes and forced ventilatory flows. Eur Respir J 1993; 6 (Suppl. 16): 5-40.

6. Gong H Jr. Air travel and oxygen therapy in cardiopulmonary patients. Chest 1992; 101: 1104-1113.

7. Schwartz JS, Bencowitz HZ, Moser KM. Air travel hypoxemia with chronic obstructive pulmonary disease. Ann Intern Med 1984; 100: 473-477.

8. Gould GA, Redpath AT, Ryan M, et al. Parenchymal emphysema measured by CT lung density correlates with lung function in patients with bullous disease. Eur Respir $J$ 1993; 6 (5): 698-704.

9. Penketh A, Higenbottam T, Hakim M, Wellwork J. Heart and lung transplantation in patients with end-stage lung disease. $\mathrm{Br}$ Med $J$ 1987; 295-311

10. Trulock EP, Egan TM, Kouchoukos NT, et al. Singlelung transplantation for severe chronic obstructive pulmonary disease. Chest 1989; 96(4): 738-742.

11. Raffin TA. Double-lung transplantation for severe COPD: reversing the irreversible. Am Rev Respir Dis 1989; 139 (2): 301-302.

12. Breen TJ, Keck B, Hosenpud JD, White R, Daily OP. Thoracic organ transplants in the United States from October 1987 through December 1992: a report from the UNOS Scientific Registry for Organ Transplants. Clin Transpl 1993; 37-45.

\section{Appendix A: Pathology}

Pathological changes in COPD can be found in the large (central) airways, the small (peripheral) bronchi and bronchioles, and the lung parenchyma [1-4]. Changes also occur in the pulmonary circulation and, in advanced disease, in the right heart.

\section{Central airways}

The site of most of the hypersecretion of mucus, expressed clinically as chronic bronchitis, are the large airways. 
Histological studies show enlargement of tracheobronchial submucosal glands and hyperplasia of tracheobronchial surface mucous (goblet) cells. In the submucosal glands, a larger proportion of mucus is acidic [5]. Recent data indicate that airway wall inflammation is also present, even in the early stages; it consists predominantly of mononuclear cells in the mucosa [6-10], and neutrophils in airway fluid [11-13]. Recent reports indicate that eosinophils may also contribute [13-15]. Upregulation of vascular adhesion molecules may increase recruitment of inflammatory cells [16-18]. Atrophic changes in cartilage have been reported in advanced stages.

\section{Peripheral airways}

Small bronchi and bronchioles are the major sites of increased airflow resistance in COPD [19, 20]. Various terms have been used to describe these changes, for example, small or peripheral airway disease or chronic obstructive bronchiolitis. The changes are characterized histopathologically by the appearance and increase in number of goblet cells, increased intraluminal mucus, inflammation, increased wall muscle mass, fibrosis, obliteration and airway narrowing [21, 22]. There is also loss of alveolar attachments to bronchioles [22, 23].

\section{Lung parenchyma}

Emphysema is defined anatomically as a permanent destructive enlargement of airspaces distal to the terminal bronchioles, without obvious fibrosis; the last characteristic is much debated [24]. Tortuosity and stenosis of bronchioles may occur as a consequence of the loss of alveolar attachments, emphysema, or reduction of elastic recoil.

Two major patterns of emphysema, with distinct functional consequences, are recognized, panacinar and centriacinar $[4,25]$. Panacinar emphysema involves destruction of the entire acinus. In centriacinar emphysema, respiratory bronchioles, alveolar ducts, and alveoli at the centre of the acinus are destroyed, but surrounding alveoli remain intact. An additional form is paraseptal emphysema, which affects areas adjacent to the connective tissue septa [4]. Widespread loss of alveolar wall surface area (per unit volume of lung) may be detected microscopically, even when emphysema cannot be detected macroscopically [26-28].

\section{Other changes}

In patients with more advanced COPD, changes also occur in pulmonary circulation, the right heart, and respiratory muscles. With alveolar hypoxia, the medial vascular smooth muscle extends distally to vessels that normally lack muscle and intimal thickening. Loss of the vascular bed occurs as a consequence of emphysema [4]. Right ventricular enlargement due to dilatation and/or hypertrophy is not uncommon. Atrophy of the diaphragm occurs in some cases [29].

\section{Structure-function relationships}

The pathological abnormalities in the airway can contribute to the increased resistance to flow by: 1) lumen obstruction by mucus; 2) changes in the properties of lining fluid; 3) increased wall thickening and decreased airway diameter; 4) smooth muscle contraction; 5) loss of alveolar attachments; and 6) obliteration of small airways.

Each of these changes may contribute to the airway hyperresponsiveness often found in patients with COPD. When these changes are mild and not accompanied by an obvious reduction in maximum expiratory flow, the increased resistance in the small airways may be detected by tests that assess the inhomogeneous functional behaviour of the lung.

Emphysema results in loss of lung recoil, which may appear early in the development of panacinar emphysema. In patients with mild to moderate airflow limitation, the decrease in maximum flow could be secondary to either loss of recoil or small airway abnormalities such as inflammation, deformity, narrowing, and obliteration. The predominant view favours emphysema as the most important factor in the limitation of airflow in severe COPD. Changes in the small airways play a greater role in mild to moderate COPD $[30,31]$.

\section{References}

1. Reid L. Measurement of the bronchial mucous gland layer: a diagnostic yardstick in chronic bronchitis. Thorax 1960; 15: 132-141.

2. Wright JL, Lawson LM, Paré PD, Wiggs BJ, Kennedy S, Hogg JC. Morphologic features of peripheral airways in current smokers and ex-smokers. Am Rev Respir Dis 1983; 127: 474-477.

3. Nagai A, West WW, Paul JL, Thurlbeck WM. The National Institutes of Health intermittent positive-pressure breathing trial: pathology studies. 1. Interrelationship between morphologic lesions. Am Rev Respir Dis 1985; 132: 937-945.

4. Lamb D. Chronic obstructive pulmonary disease: pathology. In: Brewis RAL, Gibson GJ, Geddes DM, eds. Respiratory Medicine. London, Bailliere Tindall, 1990; pp. 497-507.

5. Jeffery PK. Chronic obstructive pulmonary disease and cigarette smoke-induced epithelial damage. 1992; 2: 136-143.

6. Jeffery PK. Comparative morphology of the airways in asthma and chronic obstructive pulmonary disease. Am J Respir Crit Care Med 1994; 150: S6-S13.

7. Mullen JBM, Wright JL, Wiggs BR, Paré PD, Hogg JC. Structure of central airways in current smokers and exsmokers with and without mucus hypersecretion. Thorax 1987; 42: 843-846.

8. Fournier M, Lebargy F, Le Roy Ladurie F, Lenormand E, Pariente R. Intraepithelial T-lymphocyte subsets in the airways of normal subjects and of patients with chronic bronchitis. Am Rev Respir Dis 1989; 140: 737-742.

9. Saetta M, Di Stefano A, Maestrelli P, et al. Activated T-lymphocytes and macrophages in bronchial mucosa of subjects with chronic bronchitis. Am Rev Respir Dis 1993; 147: 301-306.

10. Ollerenshaw SL, Woolcock AJ. Characteristics of the inflammation in biopsies from large airways of subjects 
with asthma and subjects with chronic airflow limitation. Am Rev Respir Dis 1992; 145: 922-927.

11. Thompson AB, Daughton D, Robbins RA, Ghafouri MA, Oehlerking M, Rennard SI. Intraluminal airway inflammation in chronic bronchitis: characterization and correlation with clinical parameters. Am Rev Respir Dis 1989; 140: $1527-1537$.

12. Linden M, Rasmussen JB, Piitulainen E, et al. Airway inflammation in smokers with nonobstructive and obstructive chronic bronchitis. Am Rev Respir Dis 1993; 148: 1226-1232.

13. Lacoste J-Y, Bousquet J, Chanez P, et al. Eosinophilic and neutrophilic inflammation in asthma, chronic bronchitis, and chronic obstructive pulmonary disease. $J$ Allergy Clin Immunol 1993; 92: 537-548.

14. Saetta M, Di Stefano A, Maestrelli P, et al. Airway eosinophilia in chronic bronchitis during exacerbations. Am J Respir Crit Care Med 1994; 150: 1646-1652.

15. Jensen EJ, Pedersen B, Schmidt E, Venge P, Dahl R. Serum eosinophilic cationic protein and lactoferrin related to smoking history and lung function. Eur Respir $J$ 1994; 7: 927-933.

16. Di Stefano A, Maestrelli P, Roggeri A, et al. Upregulation of adhesion molecules in the bronchial mucosa of subjects with chronic obstructive bronchitis. Am J Respir Crit Care Med 1994; 149: 803-810.

17. Vignola AM, Campbell AM, Chanez P, et al. HLA-DR and ICAM-1 expression of bronchial epithelial cells in asthma and chronic bronchitis. Am Rev Respir Dis 1993; 148: 689-694.

18. Riise GC, Larsson S, Lofdahl C-G, Andersson BA. Circulating cell adhesion molecules in bronchial lavage and serum in COPD patients with chronic bronchitis. Eur Respir J 1994; 7: 1673-1677.

19. Hogg JC, Macklem PT, Thurlbeck WM. Site and nature of airway obstruction in chronic obstructive lung disease. N Engl J Med 1968; 278: 1355-1360.

20. Verbeken EK, Cauberghs M, Mertens I, Lauweryns JM, van de Woestijne KP. Tissue and airway impedance of excised normal, senile, and emphysematous lungs. $J$ Appl Physiol 1992; 72: 2343-2353.

21. Cosio MG, Hale KA, Niewoehner DE. Morphologic and morphometric effects of prolonged cigarette smoking on the small airways. Am Rev Respir Dis 1980; 122: 265-271.

22. Wright JL, Hobson JE, Wiggs B, Paré PD, Hogg JC. Airway inflammation and peribronchial attachments in the lungs of nonsmokers, current smokers and ex-smokers. Lung 1988; 166: 277-286.

23. Saetta M, Ghezzo H, Wong DK, et al. Loss of alveolar attachments in smokers: a morphometric correlate of lung function impairment. Am Rev Respir Dis 1985; 132: 894-900.

24. Snider GL, Kleinerman J, Thurlbeck WM, Bengali ZH. The definition of emphysema: report of a National Heart and Blood Institute, Division of Lung Diseases, workshop. Am Rev Respir Dis 1985; 132: 182-185.

25. Kim WD, Eidelman DH, Izquierdo JL, Ghezzo H, Saetta MP, Cosio MG. Centrilobular and panlobular emphysema in smokers: two distinct morphologic and functional entities. Am Rev Respir Dis 1991; 144: 1385-1390.

26. Gillooly M, Lamb D. Microscopic emphysema in relation to age and smoking habit. Thorax 1993; 48: 491-495.

27. Lamb D, McLean A, Gillooly M, Warren PM, Gould GA, MacNee W. Relation between distal airspace size, bronchiolar attachments, and lung function. Thorax 1993; 48: 1012-1017.

28. Hogg JC, Wright JL, Wiggs BR, Coxson HO, Saez AO,
Paré PD. Lung structure and function in cigarette smokers. Thorax 1994; 49: 473-478.

29. Arora NS, Rochester DF. COPD and human diaphragm muscle dimensions. Chest 1987; 91: 719-724.

30. Snider GL. Chronic obstructive pulmonary disease: a continuing challenge. Am Rev Respir Dis 1986; 133: 942-944.

31. Thurlbeck WM. Chronic airflow obstruction: correlation of structure and function. In: Petty TL, ed. Chronic Obstructive Pulmonary Disease. New York, Marcel Dekker, 1985; pp. 129-203.

\section{Appendix B: Pathophysiology}

\section{Evolution of the disease}

The early stages of COPD are characterized by unevenly distributed narrowing of peripheral airways. As the disease progresses, FEV1 and VC decrease and RV increases. The rate of decline in FEV1 is greater than in normal subjects. Total airway resistance and inequality in ventilation/perfusion ratio $\left(V^{\prime} / Q^{\prime}\right)$ increase. When emphysema develops, lung elastic recoil and $K \mathrm{CO}$, the transfer of carbon monoxide per litre of alveolar volume, decrease, while static lung compliance and total lung capacity increase.

At all stages of COPD, irrespective of the presence or absence of emphysema, $V^{\prime} / Q^{\prime}$ inequality is the major mechanism impairing gas exchange and leading to arterial hypoxaemia [1]. Limitation of alveolar end-capillary diffusion of oxygen is seen neither at rest nor during exercise. Any increased intrapulmonary shunt is negligible in the stable chronic condition.

In patients with severe, advanced COPD, a variety of abnormal $V^{\prime} / Q^{\prime}$ distributions may be found. Some lung units have very high $V^{\prime} / Q^{\prime}$, and most of the ventilation occurs in the zone of higher $V^{\prime} / Q^{\prime}$. In another pattern, a large proportion of blood flow perfuses lung units with very low $V^{\prime} / Q^{\prime}$. Another pattern combines both high and low $V^{\prime} / Q^{\prime}$ areas $[2,3]$. High $V^{\prime} / Q^{\prime}$ units probably represent emphysematous regions with alveolar destruction and loss of pulmonary vasculature. Low $V^{\prime} / Q^{\prime}$ units may represent areas with partially blocked airways. Most patients have mild to moderate increase in dead space. The absence of shunt suggests that collateral ventilation and hypoxic pulmonary vasoconstriction are very efficient, or that airway occlusion is not functionally complete.

Correlations between routine lung function tests and respiratory blood gases or patterns of $V^{\prime} / Q^{\prime}$ distribution are poor. However, significant hypoxaemia or hypercapnia is rare with FEV1 $>1.0 \mathrm{~L}$.

With increasing severity of airflow obstruction, expiration becomes flow-limited during tidal breathing. Initially, this occurs during exercise, but later it is also seen at rest. The increase in functional residual capacity (FRC) is due in part to static factors, such as loss of lung elastic recoil, and in part to dynamic factors at the end of expiration. The rate of lung emptying is slowed, and the interval between inspiratory efforts does not allow expiration to the relaxation volume of the respiratory system; this leads to dynamic pulmonary hyperinflation. 
This end-expiratory recoil pressure of the total respiratory system has been termed intrinsic positive endexpiratory pressure (PEEPi) $[4,5]$. PEEPi is an inspiratory threshold load that must be countered by the contracting inspiratory muscles to create negative alveolar pressure and to start inspiration. The increase in FRC can impair inspiratory muscle function and co-ordination, although the contractility of the diaphragm, when normalized for lung volume, seems to be preserved [6]. However, chronic hypercapnia is related to inspiratory muscle dysfunction [7]. Because of the increased mechanical workload, the energy consumption of the inspiratory muscles at any given level of minute ventilation is greater than in normal subjects. Respiratory drive is increased to maintain minute ventilation, which generally remains within normal limits [8].

Hypoxic pulmonary vasoconstriction may be present. This may result in pulmonary hypertension and right heart dysfunction.

\section{Acute exacerbations and respiratory failure}

Acute respiratory failure is characterized by significant deterioration of arterial blood gas tensions (hypoxaemia and hypercapnia). The severity of $V^{\prime} / Q^{\prime}$ abnormalities increases during acute exacerbations and improves slowly over a few weeks. The $V^{\prime} / Q^{\prime}$ abnormalities contribute to the increase in $P \mathrm{a}, \mathrm{CO}_{2}$, which is enhanced by alveolar hypoventilation. Changes in cardiac output, overall ventilation, and oxygen consumption may affect arterial respiratory gases [3]. Patients needing mechanical ventilation have a mild to moderate intrapulmonary shunt, suggesting that some airways are completely occluded, possibly by bronchial secretions [3].

Airway resistance, end-expiratory lung volume, and PEEPi increase substantially during acute respiratory failure [9]. The increase in elastic load may exceed the increase in resistive load. Because of expiratory airflow limitation during tidal breathing, the compensatory mechanisms must be inspiratory: increased lung volume and increased inspiratory drive. Minute ventilation is normal or greater, but the breathing pattern is abnormal, with decreased tidal volume and increased ventilatory frequency. Mouth occlusion pressure, an index of overall neuromuscular drive, is markedly increased, compared with the pressure in the stable condition [10]. Whether the high level of inspiratory muscle activity causes respiratory muscle fatigue is still a matter of debate. Indirect measurements favour this hypothesis, both in spontaneously breathing patients and during weaning from mechanical ventilation.

The mechanisms controlling ventilation and breathing patterns are still uncertain. Both the hypoxic and hypercapnic drives to breathe play important roles. The influence of breathing pattern on arterial blood gas tensions remains uncertain. Administration of oxygen corrects hypoxaemia [11] but worsens $V^{\prime} / Q^{\prime}$ balance, which contributes to the increase in $P \mathrm{a}, \mathrm{CO}_{2}$. The clinical consequences of hypercapnia depend on the underlying acid-base status, because hypercapnia acts primarily through changes in hydrogen ion activity.

\section{References}

1. Barberü JA, Ramirez J, Roca J, Wagner PD, SanchezLloret J, Rodriguez-Roisin R. Lung structure and gas exchange in mild chronic obstructive pulmonary disease. Am Rev Respir Dis 1990; 141: 895-901.

2. Wagner PD, Dantzker DR, Dueck R, Clausen JL, West JB. Ventilation-perfusion inequality in chronic obstructive pulmonary disease. J Clin Invest 1977; 59: 203-216.

3. Rodriguez-Roisin R, Roca J. Pulmonary gas exchange. In: Calverley PMA, Pride NB, eds. Chronic obstructive pulmonary disease. London, Chapman and Hall, 1995; 161-184.

4. Dal Vecchio L, Polese G, Poggi R, Rossi A. "Intrinsic" positive end-expiratory pressure in stable patients with chronic obstructive pulmonary disease. Eur Respir $J$ 1990; 3: 74-80.

5. Ninane V, Yernault JC, De Troyer A. Intrinsic PEEP in patients with chronic obstructive pulmonary disease. Am Rev Respir Dis 1993; 148: 1037-1042.

6. Similowski T, Yan S, Gauthier AP, Macklem PT, Bellemare F. Contractile properties of the human diaphragm during chronic hyperinflation. N Engl J Med 1991; 325: 917-923.

7. Begin P, Grassino A. Inspiratory muscle dysfunction and chronic hypercapnia in chronic obstructive pulmonary disease. Am Rev Respir Dis 1991; 143: 905-912.

8. Sorli J, Grassino A, Lorange G, Milic-Emili J. Control of breathing in patients with COPD. Clin Sci Mol Med 1978; 54: 295-304.

9. Rossi A, Polese G, De Sandre G. Respiratory failure in chronic airflow obstruction: recent advances and therapeutic implications in the critically ill patient. Eur J Med 1992; 1: 349-357.

10. Derenne J-P, Fleury B, Pariente R. Acute respiratory failure of chronic obstructive pulmonary disease. $\mathrm{Am}$ Rev Respir Dis 1988; 138: 1006-1033.

11. Tardif C, Bonmarchand G, Gibson J-F, et al. Respiratory response to $\mathrm{CO}_{2}$ in patients with chronic obstructive pulmonary disease in acute respiratory failure. Eur Respir $J$ 1993; 6: 619-624.

\section{Appendix C: Epidemiology}

\section{Mortality}

Mortality rates from COPD and allied conditions vary widely between countries. Whilst the differences may be due to differences in exposure to risk factors, to a large extent methodological problems with death certification or coding [1] account for the high intercountry variation.

When International Classification of Diseases (ICD) codes 490-493 are used, mortality rates for males range from 41.4 per 100,000 in Hungary to 2.3 per 100,000 in Greece, but they may change appreciably when code 496 is considered (fig. 6). Because coding is not homogeneous in all European countries, mortality rates for COPD may also include deaths from asthma. In countries where asthma death rates can be separated, COPD is clearly associated with the highest burden of mortality. Furthermore, increases in COPD death rates in Europe are projected in the future [2]. 


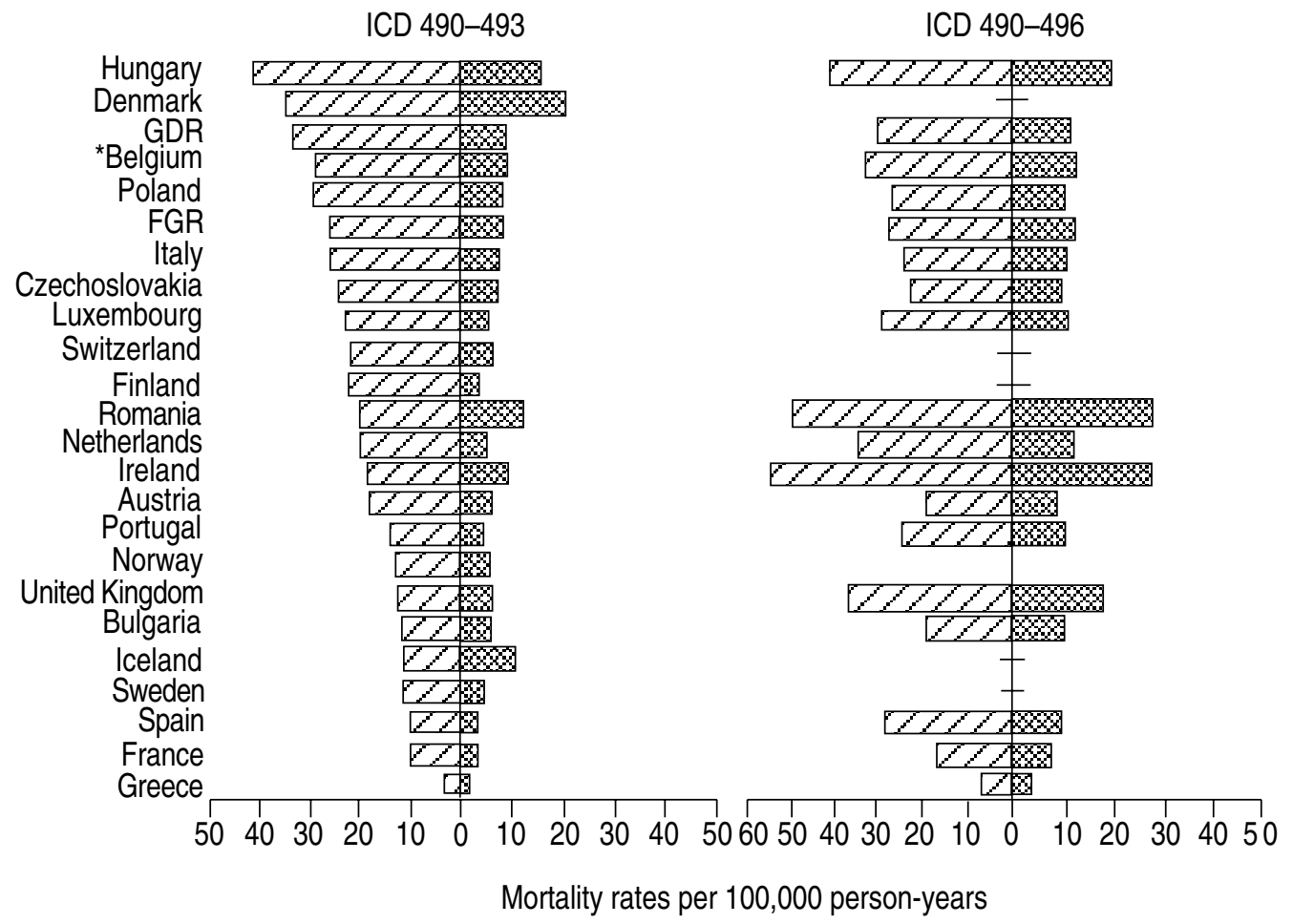

Fig. 6. - Chronic obstructive pulmonary disease (COPD) age standardized mortality rates in Europe, 1988-1991. ICD 490-496=COPD and similar conditions; ICD 490=non specified bronchitis (acute and chronic); ICD 491=chronic bronchitis; ICD 492=emphysema; ICD 493=asthma; ICD 494=bronchiectasis; ICD 495=extrinsic allergic alveolitis; ICD 496=chronic obstruction of the respiratory tract not classified anywhere: *: data from 1986. GDR: German Democratic Republic; FRG: Federal Republic of Germany; ICD: International Classification of Diseases. $\angle$ : male; $\$$ : female.

\section{Morbidity}

There are no reliable government morbidity statistics for COPD across Europe. However, good evidence suggests underdiagnosis in the general population, with only about $25 \%$ of cases being diagnosed [3-5].

Morbidity from COPD is more common in men than in women, and it increases steeply with age $[6,7]$. Gender differences may be due to the higher prevalence of cigarette smoking and occupational exposure to noxious agents in men. Recent data on young cohorts [8] show an increasing tendency to smoke among women, which might influence future figures for COPD morbidity; women may be more susceptible to develop COPD when exposed to risk factors (tobacco).

According to British data for 1982-1983, respiratory diseases rank as the third most common cause of days of certified incapacity; COPD accounted for $56 \%$ of days in males and 24\% in females [9]. Without question, COPD leads to substantial disability, loss of productivity, and reduced quality of life, which worsen as the disease progresses. Its economic impact is substantial. Exacerbations and respiratory failure may necessitate hospital admission and prolonged, costly treatment. Longterm home oxygen therapy adds to the costs.

\section{Risk factors}

The main risk factors for COPD are inhaled agents, particularly cigarette smoke. The range of individual susceptibility is wide. Recognized risk factors are listed in table 4.

Table 4. - Risk factors for COPD

\begin{tabular}{lll}
\hline Degree of certainty & Environmental factors & Host factors \\
\hline Established & Cigarette smoking & $\alpha_{1}$-antitrypsin deficiency \\
& Some occupational exposures & \\
Good evidence & Air pollution (particularly $\mathrm{SO}_{2}$ & Low birth weight \\
$\quad$ and particulates) & $\begin{array}{l}\text { Childhood respiratory infection } \\
\text { Poverty, low socioeconomic status } \\
\text { Alcohol }\end{array}$ & $\begin{array}{l}\text { Atopy (high IgE) } \\
\text { Bronchial hyperresponsiveness }\end{array}$ \\
& Environmental tobacco smoke in & Family history \\
$\quad$ childhood & \\
Other occupational exposures & Genetic predisposition \\
Pdenovirus infection & Blood group A \\
Putative & Dietary deficiency of vitamin C & IgA nonsecretor \\
\hline
\end{tabular}

COPD: chronic obstructive pulmonary disease; IgE: immunoglobulin E; IgA: immunoglobulin A. 
Among occupational risks, good evidence is available that cadmium and silica cause COPD. Workers at increased risk for COPD include coal miners, construction workers who handle cement, metal workers who are subject to heat exposure from furnaces, transport workers, grain handlers, cotton workers, and workers in paper mills. Population studies have also indicated increased risks from dust exposure and, to a lesser extent, exposure to fumes [10-14].

\section{Early detection of COPD}

COPD is usually diagnosed late in its course because patients often lack symptoms, even at low FEV1, and because simple spirometry is not routinely performed. The best method for early detection is serial measurement of FEV1 and FEV1/FVC [15].

In the 1960s and 1970s, various tests of small airway function were proposed as means to detect early COPD. Several tests showed differences between smokers and nonsmokers in cross-sectional studies, including the slope of phase 3 of the nitrogen washout curve $\left(\Delta \mathrm{N}_{2} \% \cdot \mathrm{L}^{-1}\right)$, forced expiratory flow during the middle of FVC (FEF25-75), $V^{\prime} \max 50$, and density-dependent flow rates [16]. With the exception of $\Delta \mathrm{N}_{2} \% \cdot \mathrm{L}^{-1}$, none of these tests has since been shown to predict decline in lung function reliably [17]. Biological markers, (e.g. deoxyribonucleic acid (DNA) adducts, products of elastin degradation, and products of inflammatory cells, are under investigation but cannot at present be used for early detection of COPD.

\section{Natural history}

Reliable estimation of the longitudinal decline in FEV1, needed to assess progression of COPD in an individual patient, requires spirometry of high quality. Because the accepted intraindividual variability of a single test is $5 \%$ [18], measurements over at least a 4 year span are usually required.

Several epidemiological studies have shown that FEV1 declines about $20-30 \mathrm{~mL} \cdot \mathrm{yr}^{-1}$ in healthy nonsmokers after 30 yrs of age. However, wide interindividual variability has been observed [19-22]. Among smokers, 10-20\% show an accelerated decline in FEV1 [23]. Most studies in patients with COPD show a decline of $48-91 \mathrm{~mL} \cdot \mathrm{yr}^{-1}$ $[24,25]$. The most important predictor of future decline is the current rate of decline, which can be estimated from the current FEV1 [22]. Except for $\alpha_{1}$-antitrypsin deficiency, there are no laboratory tests to detect susceptible smokers. A positive family history [26] and childhood respiratory infections [27, 28] may indicate individual susceptibility.

There is no evidence that a persistent decline in FEV1 is related to acute exacerbations $[29,30]$. As the disease progresses, the complications of acute exacerbations - respiratory failure, and cor pulmonale - may develop, as well as lung cancer [31].
Table 5. - Factors related to reduced survival in COPD

Advanced age

Continued smoking

Initial FEV $1<50 \%$ predicted

Accelerated FEV1 decline

Poor bronchodilator response

Severe untreated hypoxaemia

Cor pulmonale and poor overall functional capacity

For abbreviations see legend to table 1. (Modified from Burrows [24]).

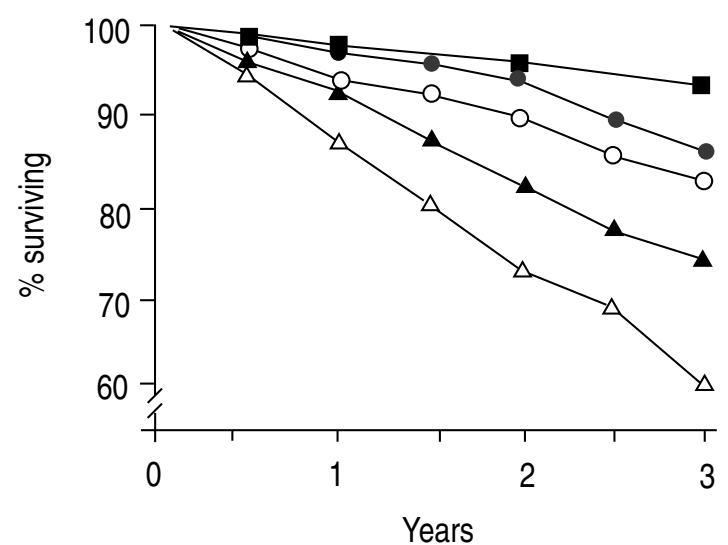

Fig. 7. - Survival in groups segregated according to baseline postbronchodilator FEV1. FEV1: forced expiratory volume in one second. —— : "normals:; — - : FEV1 $40-49 \%$ pred; $\quad$ - : FEV1 30-39\% pred; $-\triangle \quad: \mathrm{FEV}_{1}<30 \%$ pred. (Modified from ANTHONISEN [40]).

Smoking cessation clearly reduces the decline in FEV1 and reduces mortality, especially in patients with mild to moderate disease [32-37]. The beneficial effect of longterm oxygen therapy has been clearly documented [38, 39].

\section{Prognosis}

Factors associated with reduced survival are listed in table 5. The FEV1 has been found to be a good predictor of mortality from COPD (fig. 7) [40], and assessment of prognosis is an important reason to measure FEV1. Prognosis is especially affected when FEV1 is $<50 \%$ predicted. In severe COPD, with FEV1 around $1.0 \mathrm{~L}$, the 5 year survival is approximately $50 \%$ [ 41 , 42].

\section{References}

1. Farebrother MJB, Kelson MC, Heller RF, on behalf of the EEC Working Party. Death certification of farmer's lung and chronic airway diseases in different countries of the EEC. Br J Dis Chest 1985; 79: 352-360.

2. Peto R, Lopez AD, Boreham J, Thun M, Heath C Jr. Mortality from tobacco in developed countries: indirect estimation from national vital statistics. Lancet 1992; 339: $1268-1278$. 
3. Lundbäck B, Nystrom L, Rosenhall L, Stjernberg N. Obstructive lung disease in northern Sweden; respiratory symptoms assessed in a postal survey. Eur Respir $J$ 1991; 4: 257-266.

4. Viegi G, Paoletti P, Carrozzi L et al. Prevalence rates of respiratory symptoms in Italian general population samples exposed to different levels of air pollution. Environ Health Perspect 1991; 94: 95-99.

5. Manfreda J, Mas Y, Litven W. Morbidity and mortality from chronic obstructive pulmonary disease. Am Rev Respir Dis 1989; 140: S19-S26.

6. Higgins MW, Keller JB. Trends in COPD morbidity and mortality in Tecumseh, Michigan. Am Rev Respir Dis 1989; 140: S42-S48.

7. Viegi G, Paoletti P, Prediletto R, et al. Prevalence of respiratory symptoms in an unpolluted area of Northern Italy. Eur Respir J 1988; 1: 311-318.

8. International Smoking Statistics. A collection of historical data from 22 economically developed countries. In: Nicolaides-Bournan A, Wald N, Forey B, Lee P, eds. London, Wolfson Institute of Preventive Medicine, and Oxford, University Press, 1993.

9. LAIA: Lung \& Asthma Information Agency. Sickness absence from respiratory disease. London, St. George Hospital Medical School, Factsheet 92/4.

10. Becklake MR. Occupational exposures: evidence for a causal association with chronic obstructive pulmonary disease. Am Rev Respir Dis 1989; 140: S85-S91.

11. Viegi G, Prediletto R, Paoletti P, et al. Respiratory effects of occupational exposure in a general population sample in North Italy. Am Rev Respir Dis 1991; 143: 510-515.

12. Xu X, Christiani DC, Dockery DW, Warg L. Exposureresponse relationships between occupational exposures and chronic illness: a community-based study. Am Rev Respir Dis 1992; 146: 413-418.

13. Humerfelt S, Gulsvik A, Skjaerven R, et al. Decline in FEV1 and airflow limitation related to occupational exposure in men of an urban community. Eur Respir J 1993; 6: 1095-1103.

14. Burge PS. Occupation and chronic obstructive pulmonary disease (COPD). Eur Respir J 1994; 7: 1032-1034.

15. American Thoracic Society. Lung function testing: Selection of reference values and interpretative strategies. Am Rev Respir Dis 1991; 144: 1202-1218.

16. Becklake MR, Permutt S. Evaluation of tests of lung function for "screening" for early detection of chronic obstructive lung disease. In: Macklem PT, Permutt S, eds. The Lung in the Transition between Health and Disease. New York, Marcel Dekker Inc., 1979: pp. 345-387.

17. Stanescu DC, Rodenstein DO, Hoeven C, Robert A. "Sensitive tests" are poor predictors of the decline in forced expiratory volume in one second in middleaged smokers. Am Rev Respir Dis 1987; 135: 585590.

18. Quanjer PhH, Tammelin GJ, Cotes JE, et al. Lung volumes and forced ventilatory flows. Report working party "Standardization of lung function tests". European Coal and Steel Community. Eur Respir J 1993; 6 (Suppl. 16): 5-40.

19. Dockery DW, Speizer FE, Ferris BG Jr, et al. Cumulative and reversible effects of lifetime smoking on simple tests of lung function in adults. Am Rev Respir Dis 1988; 137: 286-292.

20. Fletcher C, Peto R, Tinker R, Speizer FE. The natural history of chronic bronchitis and emphysema. Oxford, Oxford University Press, 1976.
21. Kauffman F, Querleux E, Drouet D, et al. Evolution du VEMS en 12 ans et tabagisme chez 556 travailleurs de la region parisienne. Bull Eur Physiopathol Respir 1979; 15: 723-737.

22. Burrows B, Knudson RJ, Camilli AE, Lyle SK, Lebowitz MD. The "horse-racing effect" and predicting decline in forced expiratory volume in one second from screening spirometry. Am Rev Respir Dis 1987; 135: 788793.

23. Bates DV. Fate of the chronic bronchitic: a report of the ten year follow-up in the Canadian Department of Veteran's Affairs co-ordinated study of chronic bronchitis. Am Rev Respir Dis 1973; 108: 1043-1065.

24. Burrows B. Predictors of loss of lung function and mortality in obstructive lung diseases. Eur Respir Rev 1991; 1: 340-345.

25. Postma DS, Sluiter HJ. Prognosis of chronic obstructive pulmonary disease: the Dutch experience. Am Rev Respir Dis 1989; 140: S100-S105.

26. Higgins MW, Keller JB. Familial occurrence of chronic respiratory disease and familial resemblance in ventilatory capacity. J Chronic Dis 1975; 28: 239-251.

27. Burrows B, Knudson R, Lebowitz MD. The relationship of childhood respiratory illness to adult obstructive airways disease. Am Rev Respir Dis 1977; 115: 751760.

28. Burrows B. Airways obstructive diseases: pathogenetic mechanisms and natural histories of the disorders. Med Clin North Am 1990; 74: 547-559.

29. Fletcher C, Peto R. The natural history of chronic airflow obstruction. Br Med J 1977; 1: 1645-1648.

30. Murphy TF, Sethi S. State of the art. Bacterial infection on chronic obstructive pulmonary disease. Am Rev Respir Dis 1992; 146: 1067-1083.

31. Skillrud DM, Offord KP, Miller RD. Higher risk of lung cancer in chronic obstructive pulmonary disease: a prospective, matched, controlled study. Ann Intern Med 1986; 105: 503-507.

32. Hughes JA, Hutchison DCS, Bellamy D, Dowd DE, Ryan $\mathrm{KC}$, Hugh-Jones P. The influence of cigarette smoking and its withdrawal on the annual change of lung function in pulmonary emphysema. $Q J$ Med 1982; 51: $115-124$.

33. Lange $\mathrm{P}$, Groth $\mathrm{S}$, Nyboe J, et al. Effects of smoking and changes in smoking habits on the decline of FEV1. Eur Respir J 1989; 2: 811-816.

34. Kanner RE, Renzetti AD Jr, Stanish WM, Buknam HW Jr, Klauber MR. Predictors of survival in subjects with chronic airflow limitation. Am J Med 1983; 74: 249255.

35. Postma DS, De Vries K, Koeter GH, Sluiter HJ. Independent influence of reversibility of airflow obstruction and nonspecific hyperactivity on the long-term course of lung function in chronic airflow obstruction. Am Rev Respir Dis 1986; 134: 276-280.

36. Xu X, Dockery DW, Ware JM, Speizer FE, Ferris BJ Jr. Effects of cigarette smoking on rate of loss of pulmonary function in adults: a longitudinal assessment. Am Rev Respir Dis 1992; 146: 1345-1348.

37. Anthonisen NR, Connett JE, Kiley JP, et al. Effects of smoking intervention and the use of an inhaled anticholinergic bronchodilator on the rate of decline of FEV1. The Lung Health Study. J Am Med Assoc 1994; 272: 1497-1505.

38. Nocturnal Oxygen Therapy Trial. Continuous or nocturnal oxygen therapy in hypoxemic chronic obstructive lung disease: a clinical trial. Ann Intern Med 1980; 93: 391-398. 
39. Report of the Medical Research Council working party. Long-term domiciliary oxygen therapy in chronic cor pulmonale complicating chronic bronchitis and emphysema. Lancet 1981; i: 681-686.

40. Anthonisen NR, Wright EC, Hodgkin JE, and the IPPB Trial Group. Prognosis in chronic obstructive pulmonary disease. Am Rev Respir Dis 1986; 133: 14-20.

41. Langloh P, Brandli O, Schnieper R. Uberlebenswahrscheinlichkeit und prognostische Faktoren der chronischen obstruktiven Lungenkrankheit. Schweitz Med Wschr 1982; 112: 1841-1846.

42. Traver GA, Cline MG, Burrows B. Predictors of mortality in chronic obstructive pulmonary disease: a 15 year follow-up study. Am Rev Respir Dis 1979; 119: 895902.

\section{Task Force producing the statement}

Chairs: N.M. Siafakas, P. Vermeire. Definition/Pathology/Pathophysiology Subcommittee: N.B. Pride (Head), J-P. Derenne, P.K. Jeffery, D. Lamb, R. Rodriguez-Roisin, A. Rossi, M. Saetta, P. Vermeire. Epidemiology Subcommittee: P. Paoletti (Head), S. Burge, U. Costabel, G. Viegi. Clinical Assessment Subcommittee: J. Gibson (Head), W. De Backer, D. Georgopoulos, W. McNee, E. Russi, D. Stanescu, E. Weitzenblum. Treatment Subcommittee: P. Howard (Head), M. Decramer, M. Del Donno, H. Donner, H. Lode, C-G. Lofdahl, D. Olivieri, D.S. Postma, J. Rees, D. Robert. Management Subcommittee: J.C. Yernault (Head), D. Bouros, M. Cochrane, T. Higenbottam, K. Moghissi, C. Roussos, N.M. Siafakas, S. Zakinthinos. North American Advisers: A.S. Buist, K.R. Chapman, M.G. Cosio. Internal Reviewing Committee: M. Decramer, T. Higenbottam, D.S. Postma, N.B. Pride, J. Rees, N.M. Siafakas, P. Vermeire, J.C. Yernault. External Reviewers: S. Spiro, C. Giuntini, A. Woodcock. 